\title{
The Chemistry of Tributyl Phosphate at Elevated Temperatures in the Plutonium Finishing Plant Process Vessels
}

Prepared for the U.S. Department of Energy Office of Environmental Restoration and Waste Management

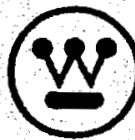

Westinghouse

Hanford Company Richland, Washington

Hanford Operations and Engineering Contractor for the

U.S. Department of Energy under Contract DE-AC06-87RL10930

Approved for Public Release 


\section{LEGAL DISCLAIMER}

This report was prepared as an account of work sponsored by an agency of the United States Government. Neither the

United States Government nor any agency thereof, nor any of their employees, nor any of their contractors, subcontractors or their employees, makes any warranty, express or implied, of assumes any legal liability or responsibility for the

accuracy, completeness, or any third party's use or the results of such use of any information, apparatus, product, or process disclosed, or represents that its use would not infringe. privately owned rights. Reference herein to any specific commercial product, process, or service by trade name, trademark, manufacturer, of othervise, does not necessarily constitute or imply its endorsement, recommendation, of favoring by the United States Government or any agency thereof or its contractors or subcontractors. The views and opinions of authors expressed herein do not necessarily state or reflect those of the United States Government or any agency thereol.

This report has been reproduced from the best available copy. Available in paper copy and microfiche.

Available to the U.S. Department of Energy and its contractors from

Office of Scientific and Technical Information

P.0. Box 62

Oak Ridge, TN 37831

(615) $576-8401$

Available to the public from the U.S Department of Commerce National Technical Information Service 5285 Port Royal Road

Soringfield VA 22161

(703) $\mathbf{4 8 7 - 4 6 5 0}$

Printed in the United States of Americs

DISCLM-1.CHP (1:01) 


\section{DISCLAIMER}

This report was prepared as an account of work sponsored by an agency of the United States Government. Neither the United States Government nor any agency thereof, nor any of their employees, makes any warranty, express or implied, or assumes any legal liability or responsibility for the accuracy, completeness, or usefulness of any information, apparatus, product, or process disclosed, or represents that its use would not infringe privately owned rights. Reference herein to any specific commercial product, process, or service by trade name, trademark, manufacturer, or otherwise does not necessarily constitute or imply its endorsement, recommendation, or favoring by the United States Government or any agency thereof. The views and opinions of authors expressed herein do not necessarily state or reflect those of the United States Government or any agency thereof. 


\section{DISCLAIMER}

Portions of this document may be illegible in electronic image products. Images are produced from the best available original document. 


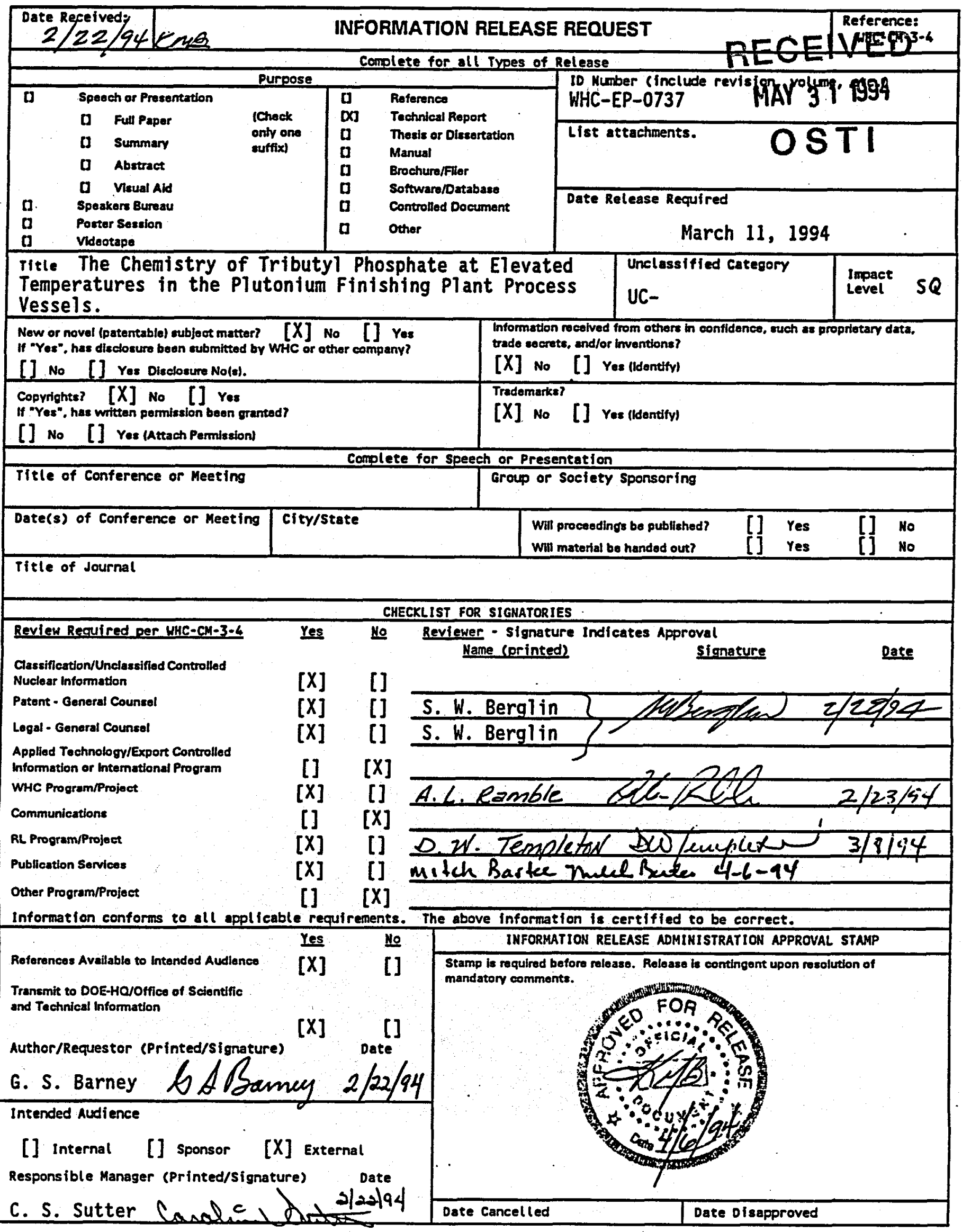




\section{The Chemistry of Tributyl Phosphate at Elevated Temperatures in the Plutonium Finishing Plant Process Vessels.}

Prepared for the U.S. Department of Energy Office of Environmental Restoration and Waste Management

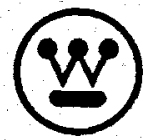

Westinghouse

Hanford Company Rictland, Washington

Hanford Operations and Engineering Contractor for the

U.S. Department of Energy under Contract DE-AC06-87RL 10930

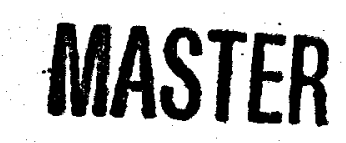

$2 \ldots$

DISTRIBUTION OF THIS DOCUMENT IS UNLUMITEO

Approved for Public Release 
(

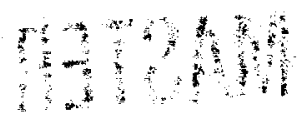

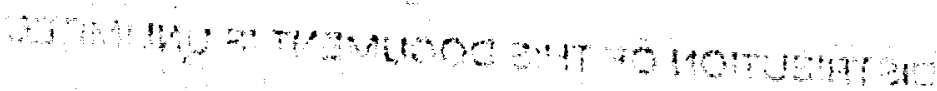

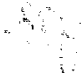


WHC-EP-0737

Document Title: The Chemistry of Tributyl Phosphate At Elevated Temperatures InThe Plutonium Finishing Plant Process Vessels

Prepared by:

Reviewed by:

Approved by:

Approved by:

Approved by: $\frac{\text { LAB amy }}{\text { G. S. Barney }}$

Fellow Scientist

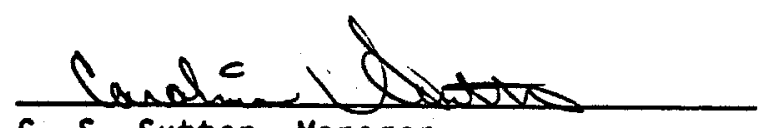

c. S. Shutter. Manager

Plutonium Process Support Laboratory

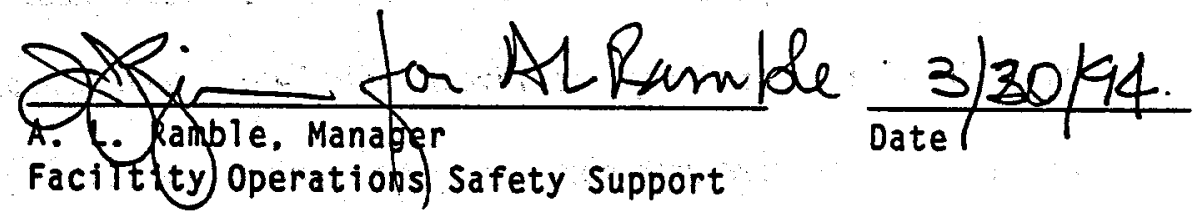

G. W. Upington

Quality Assurance Engineer

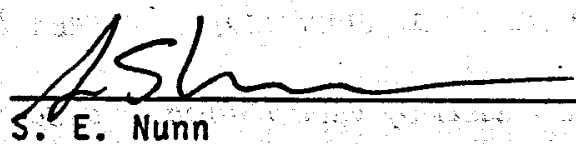

Safety Engineer

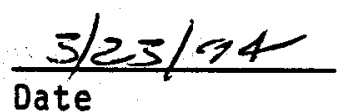

$\frac{3 / 29 / 9 y}{\text { Date }}$

iii 


\title{
THE CHEMISTRY OF TRIBUTYL PHOSPHATE AT ELEVATED TEMPERATURE IN THE PLUTONIUM FINISHING PLANT PROCESS VESSELS
}

\author{
G. S. Bamey \\ T. D. Cooper
}

\section{ABSTRACT}

Potentially violent chemical reactions of the tributyl phosphate solvent used by the Plutonium Finishing Plant at the Hanford Site were investigated. There is a small probability that a significant quantity of this solvent could be accidentally transferred to heated process vessels and react there with nitric acid or plutonium nitrate also present in the solvent extraction process. The results of laboratory studies of the reactions show that exothermic oxidation of tributyl phosphate by either nitric acid or actinide nitrates is slow at temperatures expected in the heated vessels. Less than four percent of the tributyl phosphate will be oxidized in these vented vessels at temperatures between $125^{\circ} \mathrm{C}$ and $250^{\circ} \mathrm{C}$ because the axidant will be lost from the vessels by vaporization or decomposition before the tributyl phosphate can be extensively oxidized. The net amounts of heat generated by oxidation with concentrated nitric acid and with thorium nitrate (a stand-in for plutonium nitrate) were determined to be about -150 and -220 joules per gram of tributyl phosphate initially present, respectively. This is not enough heat to cause violent reactions in the vessels. Pyrolysis of the tributyl phosphate occurred in these mixtures at temperatures of $110^{\circ} \mathrm{C}$ to $270^{\circ} \mathrm{C}$ and produced mainly 1-butene gas, water, and pyrophosphoric acid. Butene gas generation is slow at expected process vessel temperatures, but the rate is faster at higher temperatures. 


\section{WHC-EP-0737}

At $252^{\circ} \mathrm{C}$ the rate of butene gas generated was $0.33 \mathrm{~g}$ butene/min/g of tributyl phosphate present. The measured heat absorbed by the pyrolysis reaction was $228 \mathrm{~J} / \mathrm{g}$ of tributyl phosphate initially present (or $14.5 \mathrm{kcal} /$ mole of tributyl phosphate). Release of flammable butene gas into process areas where it could ignite appears to be the most serious safety consideration for the Plutonium Finishing Plant. 


\section{WHC-EP-0737}

This page intentionally left blank. 


\section{TABLE OF CONTENTS}

1:0 INTRODUCTION $\ldots \ldots \ldots \ldots \ldots \ldots \ldots \ldots \ldots \ldots \ldots \ldots \ldots \ldots \ldots \ldots$

2.0 PROCESSING INCIDENTS INVOLVING HEATED TBP SOLVENTS . . . . 2-1 2.1 TNX EVAPORATOR INCIDENT AT SAVANNAH RIVER PLANT $\ldots \ldots$ 2-1

2.2 THE 1953 HANFORD SITE CONCENTRATOR INCIDENT $\ldots \ldots \ldots \ldots$ 2-1

2.3 THE 1975 SAVANNAH RIVER DENITRATOR INCIDENT $\ldots \ldots \ldots \ldots 2-2$

2.4 THE RUSSIAN TOMSK INCIDENT $\ldots \ldots \ldots \ldots \ldots \ldots \ldots \ldots \ldots$

3.0 CONDITIONS AFFECTING RUNAWAY REACTIONS IN PROCESS VESSELS . 3-1

3.1 SEALED VERSUS VENTED SYSTEMS $\ldots \ldots \ldots \ldots \ldots \ldots \ldots \ldots .1$

3.2 HEATING AND COOLING RATES $\ldots \ldots \ldots \ldots \ldots \ldots \ldots \ldots \ldots . \ldots \ldots$

3.3 SPECIFIC ACCIDENT SCENARIOS ............... . .

4.0 EXPERIMENTAL .........................

4.1 MATERIALS AND EQUIPMENT $\ldots \ldots \ldots \ldots \ldots \ldots \ldots \ldots \ldots \ldots$ 4-1

4.2 METHODS .........................

5.0 RESULTS AND DISCUSSION $\ldots \ldots \ldots \ldots \ldots \ldots \ldots \ldots \ldots \ldots \ldots$. $\ldots \ldots \ldots$

5.1 TRIBUTYL PHOSPHATE REACTIONS WITH NITRIC ACID . . . . . 5-1

5.2 TRIBUTYL PHOSPHATE REACTIONS WITH PLUTONIUM NITRATE . 5-15

5.3 THERMAL DECOMPOSITION REACTIONS OF TBP $\ldots \ldots \ldots \ldots \ldots$ 5-20

6.0 CONCLUSIONS $\ldots \ldots \ldots \ldots \ldots \ldots \ldots \ldots \ldots \ldots \ldots \ldots \ldots \ldots \ldots$

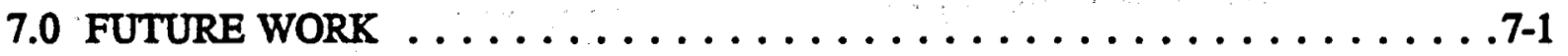

8.0 REFERENCES $\ldots \ldots \ldots \ldots \ldots \ldots \ldots \ldots \ldots \ldots \ldots \ldots \ldots \ldots \ldots \ldots \ldots \ldots \ldots \ldots \ldots$ 
WHC-EP-0737

\section{LIST OF FIGURES}

Figure 5-1. TG (..) and DTA $\$ Curves for $231.7 \mathrm{mg}$ of $20 \%$ TBP in Carbon Tetrachloride Saturated with Concentrated Nitric Acid (31.4 mg TBP, $191 \mathrm{mg}$

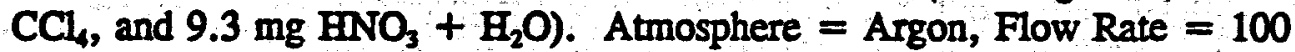
$\mathrm{cc} / \mathrm{min}$, Heating Rate $=3.0^{\circ} \mathrm{C} / \min . \ldots \ldots \ldots \ldots \ldots \ldots \ldots . . \ldots \ldots$

Figure 5-2. TG (.) and DTA $\bigcirc$ Curves for $138.0 \mathrm{mg}$ of Mixture of TBP (Previously Saturated with Concentrated Nitric Acid) and Concentrated Nitric Acid (66.9 mg TBP, and $71.1 \mathrm{mg} \mathrm{HNO}_{3}+\mathrm{H}_{2} \mathrm{O}$ ). Atmosphere = Argon, Flow Rate $=100 \mathrm{cc} / \mathrm{min}$, Heating Rate $=3.0^{\circ} \mathrm{C} / \mathrm{min} . \ldots \ldots \ldots \ldots . . . .4$

Figure 5-3. Mass Intensity Curves During Thermal Analysis of $138 \mathrm{mg}$ of Mixture of TBP (Previously Saturated with Concentrated Nitric Acid) and Concentrated Nitric Acid (66.9 mg TBP, and $71.1 \mathrm{mg} \mathrm{HNO}_{3}+\mathrm{H}_{2} \mathrm{O}$ ). Atmosphere $=$ Argon, Flow Rate $=100 \mathrm{cc} / \mathrm{min}$, Heating Rate $=3.0^{\circ} \mathrm{C} / \mathrm{min}$. (A) Mass $12($, Mass 44 (.), and Mass $56(-)$. (B) Mass $28 \circlearrowright$, Mass $30(.$.$) , and Mass 46 \sqcup \ldots$. . 5-5

Figure 5-4. Mass Intensity Curves During Thermal Analysis of $138 \mathrm{mg}$ of Mixture of TBP (Previously Saturated with Concentrated Nitric Acid) and Concentrated

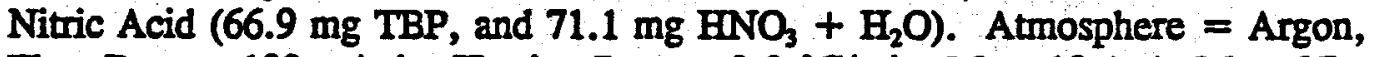
Flow Rate $=100 \mathrm{cc} / \mathrm{min}$, Heating Rate $=3.0^{\circ} \mathrm{C} / \mathrm{min}$. Mass $18($, Mass 27

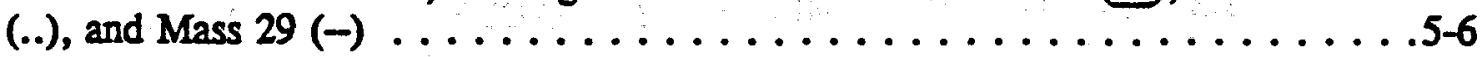

Figure 5-5. Mass Spectra of Pure TBP Heated to $251^{\circ} \mathrm{C}(\mathrm{A})$ and Pure 1-Butene Reference Gas (B). . . . . . . . . . . . . . . . . . 5-7

Figure 5-6. Mass Spectra of TBP Saturated with Concentrated Nitric Acid Heated to $144^{\circ} \mathrm{C}(\mathrm{A})$ and Pure Concentrated Nitric Acid Reference Liquid at $128^{\circ} \mathrm{C}$ (B). . . 5-8

Figure 5-7. Comparison of DTA Curves for Mixtures Containing Different Ratios of TBP/Nitric Acid. ( $39.9 \mathrm{mg} \mathrm{TBP}+14.8 \mathrm{mg} \mathrm{HNO}_{3},(.) .33.1 \mathrm{mg}$ TBP +

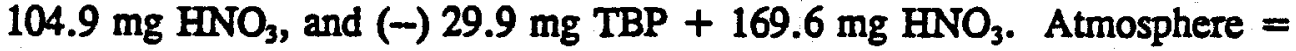
Argon, Flow Rate $=100 \mathrm{cc} / \mathrm{min}$, Heating Rate $=3.0^{\circ} \mathrm{C} / \mathrm{min} . \ldots \ldots . . .5$

Figure 5-8. Comparison of TG Curves for TBP Equilibrated with Various Aqueous Concentrations of Nitric Acid. $\cup 15.7 \mathrm{M} \mathrm{HNO}_{3},(.) .12.0 \mathrm{M} \mathrm{HNO}_{3},(-) 8.0$

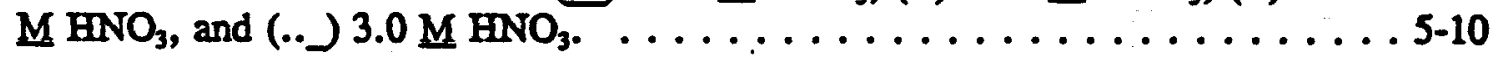

Figure 5-9. Effect of Air Atmosphere on DTA (A) and TG (B) Curves for TBP Saturated with Concentrated Nitric Acid. $(80.4 \mathrm{mg}$ TBP $+29.7 \mathrm{mg} \mathrm{HNO}$

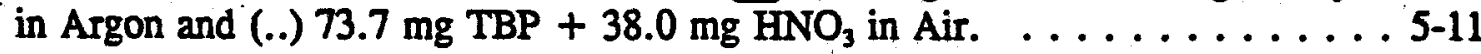


Figure 5-10. Effect of Heating Rate on DTA (A) and TG (B) Curves for TBP Saturated with Concentrated Nitric Acid. ( $37.6 \mathrm{mg} \mathrm{TBP}+20.3 \mathrm{mg} \mathrm{HNO}$, $5^{\circ} \mathrm{C} / \mathrm{min}$; (..) $39.9 \mathrm{mg}$ TBP + $14.8 \mathrm{mg} \mathrm{HNO}_{3}, 3^{\circ} \mathrm{C} / \mathrm{min}$; ( $\rightarrow 38.9 \mathrm{mg} \mathrm{TBP}+$

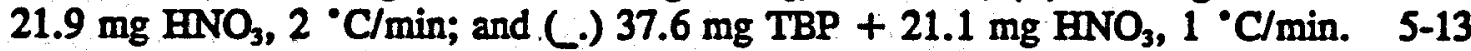

Figure 5-11. TG (..) and DTA (-) Curves for TBP Saturated with Thorium Nitrate and Concentrated Nitric Acid (39.6 mg TBP, $41.8 \mathrm{mg} \mathrm{Th}\left(\mathrm{NO}_{3}\right)_{4}$, and $25.0 \mathrm{mg}$ $\mathrm{HNO}_{3}+\mathrm{H}_{2} \mathrm{O}$ ). Atmosphere $=$ Argon, Flow Rate $=100 \mathrm{cc} / \mathrm{min}$, Heating Rate $=3.0^{\circ} \mathrm{C} / \mathrm{min} . \ldots \ldots \ldots \ldots \ldots \ldots \ldots \ldots \ldots \ldots \ldots . \ldots \ldots$

Figure 5-12. Mass Spectrum of TBP Saturated with Thorium Nitrate and Concentrated Nitric Acid Heated to $161^{\circ} \mathrm{C}(\mathrm{A})$ and $245^{\circ} \mathrm{C}(\mathrm{B}) \ldots \ldots \ldots \ldots \ldots \ldots . . \ldots$ 5-17

Figure 5-13. Mass Spectrum of TBP Saturated with Thorium Nitrate and Concentrated Nitric Acid Heated to $302^{\circ}$ C. . . . . . . . . . . . . . . . . . . . 5-18

Figure 5-14. Mass Spectra of Pure 1-Butyl Nitrate Standard Heated to $129^{\circ} \mathrm{C}$ (A) and Pure 1-Butene Standard (B). . . . . . . . . . . . . . . . . . . . 5-19

Figure 5-15. TG (..) and DTA $\square$ Curves for a Mixture of TBP $(28.3 \mathrm{mg})$ and Uranyl Nitrate Solution (229.5 $\mathrm{mg}$ of a $111 \mathrm{mg} \mathrm{U} / \mathrm{mL}$ solution). Atmosphere $=$ Argon, Flow Rate $=100 \mathrm{cc} / \mathrm{min}$, Heating Rate $=3.0^{\circ} \mathrm{C} / \mathrm{min} . \ldots \ldots . \ldots 5-20$

Figure 5-16. Comparison of TG (A) and DTA (B) Curves for Pure TBP (..) and TBP Saturated with Concentrated Nitric Acid $\cup$. $100.1 \mathrm{mg}$ of Pure TBP and 80.4

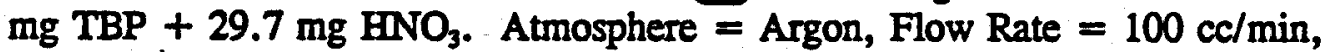

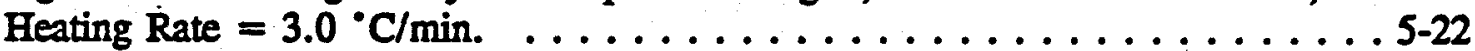

Figure 5-17. Comparison of Mass 56 Intensities for Pure TBP (**) and TBP Saturated with Concentrated Nitric Acid () over a $20^{\circ} \mathrm{C}$ to $360^{\circ} \mathrm{C}$ Temperature Range. $100.1 \mathrm{mg}$ of Pure TBP and $80.4 \mathrm{mg}$ TBP $+29.7 \mathrm{mg} \mathrm{HNO}$. Atmosphere = Argon, Flow Rate $=100 \mathrm{cc} / \mathrm{min}$, Heating Rate $=3.0^{\circ} \mathrm{C} / \mathrm{min} . \ldots \ldots . . .55$

Figure 5-18. Arrhenius Plot of Butene Generation Rates Versus Temperature. . . . . 5 5-24 


\section{WHC-EP-0737}

\section{LIST OF TABLES}

Table 4-1. Sources and Purity of Reagent Grade Chemicals Used in Experimental Work ............................

Table 5-1. Effects of Nitric Acid Concentration on TBP-Nitric Acid Reactions . . . . 5-10

Table 5-2. Measured Net Heat Evolved from Heated TBP-Nitric Acid Mixtures . . . 5-12

Table 5-3. Processes Occurring During Heating of TBP-Nitric Acid Mixtures . . . . . 5-15

Table 5-4. Rates of Butene Gas Generation from TBP Pyrolysis . . . . . . . . 5-21 


\section{ACRONYMS AND TERMS}

$\begin{array}{ll}\text { DBP } & \text { Dibutyl Phosphate } \\ \text { DOE } & \text { U.S. Department of Energy } \\ \text { DTA } & \text { Differential Thermal Analysis } \\ \text { J/g } & \text { Joules per gram } \\ \text { PFP } & \text { Plutonium Finishing Plant } \\ \text { psi } & \text { Pound-force per square inch } \\ \text { SRP } & \text { Savannah River Project } \\ \text { TBP } & \text { Tributyl Phosphate } \\ \text { TG } & \text { Thermogravimetric } \\ \text { UNH } & \text { Uranyl Nitrate Hexahydrate }\end{array}$


WHC-EP-0737

This page intentionally left blank. 


\section{THE CHEMISTRY OF TRIBUTYL PHOSPHATE AT ELEVATED TEMPERATURES IN PLUTONIUM FINISHING PLANT PROCESS VESSEIS}

\subsection{INTRODUCTION}

The Plutonium Finishing Plant (PFP) at the Fanford Site uses a solvent extraction process to purify plutonium nitrate in nitric acid feed solutions. The organic plutonium extractant is a solution of $20 \%$ tributyl phosphate (by volume) in carbon tetrachloride. There is a slight probability that some of this solvent (or degraded solvent) could be accidentally transferred to heated process vessels in the PFP that are used to concentrate aqueous plutonium solutions or to dissolve plutonium scrap. If present, carbon tetrachloride would be rapidly boiled away and the tributyl phosphate (TBP) would remain to be heated with aqueous nitric acid and plutonium nitrate solutions. Both nitric acid and plutonium nitrate are strong oxidizers at high temperatures and can oxidize TBP with the release of heat. This causes a concem that a violent reaction might occur in process vessels that could cause injury, damage to equipment, or release of plutonium to the environment. Violent reactions involving TBP solvents, nitric acid, and uranyl nitrate have occurred in the past at similar processing facilities. These incidents are briefly reviewed in Section 2.0.

The objective of the present study was to determine if violent reactions could occur between TBP and nitric acid or plutonium nitrate under conditions expected in heated process vessels at the PFP. The study required identifying reactions occurring over a relevant temperature range, measuring the reaction heat released or absorbed for these reactions, and estimating the rate of the reactions. These data were obtained using a thermal analyzer capable of mass spectrometric analysis of gases evolved from the sample. This instrument measures sample weight loss, measures heat flow to and from the sample, and identifies and quantifies gases evolved from the sample as it is heated. All these data are obtained simultaneously which allows identification of reaction products, measurement of reaction rates, and measurement of reaction enthalpy changes and phase conversion enthalpy changes.

The reactions were studied in a platinum reaction crucible in flowing argon gas at atmospheric pressure. The inert gas simulated accident conditions where most of the air in heated vessels will be displaced by vapor from the boiling liquids (carbon tetrachloride, water, nitric acid). The boiling points of these liquids are lower than the operating temperatures of the vessels and the volume of the vapor resulting from heating the liquids is much greater than the volume of the vessels. Thus, most of the air will be effectively displaced by the vapors. The vessels are all open to the atmosphere under normal operating conditions and have pressure relief devices that open if internal pressure rises above atmospheric pressure.

Previous studies of TBP reactions with nitric acid were performed by Nichols et al. (1960). After the TNX evaporator explosion at the Savannah River Plant, Nichols measured 
the reaction rate of TBP that had been equilibrated with varying concentrations of nitric acid. He identified the gaseous products which traversed a water.seal and postulated the reactions producing those gases. From measured rates and the postulated reactions, Nichols modeled the reactions and calculated self-heating rates for several TBP systems. The report also presents cooling rates for simple uninsulated tanks of varying geometries and predicted instability temperatures. Nichols' work showed that the decomposition of the TBP nitrate complex is pseudo-first order and the report calculated the Arrhenius frequency factor and the activation energy for the reaction. Nichols did not separate the reaction of the uranyl nitrate TBP adduct from the reaction of the nitric acid TBP adduct. Nichols et al. 1953; averaged calculations for the degradation of both the uranyl-TBP and nitric acid-TBP adducts. The frequency factor and activation energies of Nichols must therefore be modified accordingly.

Colvin et al. (1953) reported a description of the TNX evaporator explosion at Savannah River Plant (SRP) and provided useful experimental data on the explosive reactions. The report showed that when $40 \%$ uranyl nitrate-8.8\% nitric acid solutions (with various amounts of TBP) were heated at 0.1 to $1.0^{\circ} \mathrm{C}$ per minute, the initiation of rapid exothermic reactions occurred in an open system at 140 to $160^{\circ} \mathrm{C}$. The reaction typically resulted in a rapid evolution of oxides of nitrogen, foaming, rapid rise in pot temperature, and solidification or drying out of the residue. In a sealed bomb, the initiation temperature (minimum temperature for self-accelerating reactions) decreased lineariy from 195 to $130^{\circ} \mathrm{C}$ as the uranyl nitrate concentration in the aqueous phase increased from 47 to 84.5 wt\% (this corresponds to an aqueous phase consisting of uranyl nitrate tetrahydrate). Varying the uranyl nitrate/TBP ratio had a minimal effect on the initiation temperature. In the same sealed one liter bomb, 22 grams of TBP and 75 grams of $68 \%$ nitric acid initiated at $160^{\circ} \mathrm{C}$ and gave a maximum pressure of 4,600 psi with a maximum pressure rate rise of $250,000 \mathrm{psi} / \mathrm{sec}$.

Harmon et al. (1976) observed the thermal denitration of the uranium nitrate-TBP adduct and concluded that the thermal decomposition occurs in one gradual weight loss below $170^{\circ} \mathrm{C}$; however, above $170^{\circ} \mathrm{C}$, the sample weight loss occurs in two steps. The first step corresponds to the conversion of TBP in the adduct to dibutyl phosphate (DBP) with butyl nitrate as a product which is rapidly oxidized. The second step corresponds to the pyrolysis of DBP within the complex to phosphoric acid and the formation of volatile butene. Gases released from the reaction were $\mathrm{N}_{2}, \mathrm{NO}, \mathrm{N}_{2} \mathrm{O}, \mathrm{CO}, \mathrm{CO}_{2}$ and butene. Essentially no hydrocarbons other than butene were found. Below $185^{\circ} \mathrm{C}$, the gases evolved were nonflammable.

Wagner (1952 and 1953) combined solutions of uranyl nitrate, Shell spray base, TBP, 90\% nitric acid, and "red oil" in varying proportions and reported the temperatures at which foaming or vigorous reactions occurred. The report showed that no vigorous reactions or explosions occurred under reflux conditions and that the temperature must be $146^{\circ} \mathrm{C}$ or more before vigorous reactions were encountered. 
Steiglitz, et al. (1986) experimented with an aqueous phase containing nitric acid, uranyl nitrate, and dissolved and entrained TBP. The report concluded that steam stripping removes all significant dissolved TBP from process vessels. Entrained TBP can survive the steam stripping process to yield a $\mathrm{UO}_{2}\left(\mathrm{NO}_{3}\right)_{2}$-TBP.DBP complex. The thermal decomposition of $\mathrm{UO}_{2}\left(\mathrm{NO}_{3}\right)_{2} \cdot 2 \mathrm{TBP}$ was demonstrated to occur in two steps:

- At $225^{\circ} \mathrm{C}$ an exothermic reaction was observed where two butyl groups are removed and oxidized by nitrate $(\Delta \mathrm{H}=-331 \mathrm{~kJ} / \mathrm{mole} \pm 15 \%)$.

- At $289^{\circ} \mathrm{C}$, dealkylation of four butyl groups occurs to produce butene $(\Delta \mathrm{H}=216 \mathrm{~kJ} / \mathrm{mole} \pm 14 \%)$.

Pugh (1954) experimented with plutonium nitrate-TBP mixtures. This report concluded that violent reactions were initiated above $150^{\circ} \mathrm{C}$, but explosions were not observed. This report offers no new experiments designed to elucidate the chemical reactions, mechanisms, or rates.

Review documents dealing with TBP-nitrate systems were prepared by Campbell and Mailen (1988) and Perkins et al. (1977). 
WHC-EP-0737

This page intentionally left blank. 
WHC-EP-0737

\subsection{PROCESSING INCIDENTS INVOLVING HEATED TBP SOLVENTS}

\subsection{TNX EVAPORATOR INCIDENT AT SAVANNAH RIVER PLANT}

The TNX semiworks evaporator incident occurred on January 12, 1953 (Colvin et al. 1953). A uranyl nitrate solution was being concentrated to remove excess nitric acid and was inadvertently over concentrated to the point of "incipient calcination." The temperature measurement device became inoperative and the density measurement was off-scale.

The reaction caused a "rumbling noise," followed by the emission of orange fumes and a "high-pitched roar," occurring immediately before rupture of the pot. The TNX evaporator contained steam coils in a 3-ft-diameter pot, which was topped, successively, by a 6-ft-diameter shell and a 2.5-ft-diameter tower containing eight bubble-cap trays. After the incident, the lower bubble-cap trays became partially plugged with solids, probably as a result of the foaming of the liquid during the decomposition reaction. The resulting increased pressure, because of the plugging, caused the reaction to be more violent.

Examination of the residue after the incident showed the presence of hydrated uranium compounds and therefore the temperature of $<200^{\circ} \mathrm{C}$. However, $\mathrm{UO}_{2}$ was found in the room outside the evaporator, so localized temperatures exceeded $1,000^{\circ} \mathrm{C}$. The residue was found to contain phosphorus from the TBP. It was estimated that 80 pounds of TBP had been present in the evaporator, probably complexed with uranyl nitrate as $\mathrm{UO}_{2}\left(\mathrm{NO}_{3}\right)_{2} \cdot 2 \mathrm{TBP}$.

\subsection{THE 1953 HANFORD SITE CONCENTRATOR INCIDENT}

This incident occurred during the first operation of a new uranium concentrator when a feed pump to the concentrator failed (Sege 1953). As a result of this failure, the evaporation process continued to a higher concentration than normal and the temperature increased to "incipient calcination. The decomposition reaction was characterized by emission of brown fumes from the concentrator vent, but no destruction of the equipment occurred.

The concentrator contained vertical-tube heaters used to boil the solution in a 3-ft-diameter steam chest. The stripping section, located above the boiler, was $6 \mathrm{ft}$ in diameter with an 18-ft-long section packed with 2-in Raschig rings for removal by steam-stripping of organic phase that might accompany the aqueous feed. Above the stripping section, there was an additional 3-ft-long packed section for de-entrainment. The vapor exiting the tower was condensed by a jet condenser that was vented to the atmosphere. The concentrator was fed directly from the aqueous effluent de-entrainment section of the uranium strip column, using a pump and a control valve to regulate the column interface.

Using manual control, the steam flow (100 psi steam supply) was adjusted to maintain a specified liquid density in the concentrator as dilute feed was pumped in from the strip 
column. Feed flow was interrupted several times because of interactions between the feed pump, the flow control valve, and the column interface controller. During one such interruption, the liquid level fell below the upper dip tube of a differential-pressure density device, thereby giving an indicated density reading lower than the true value. As a result, the steam increased to excessive values. The reaction that followed caused emission of brown fumes from the condenser vent, a hissing noise, and the odor of butyric acid.

The rapid evolution of gases was carried by the large cross-sectional area of the stripping section, and the equipment was not significantly damaged. However, the Raschig rings showed evidence of damage and the feed distributor showed signs of being battered by the ceramic rings. The uranium content of the residue was estimated to vary from about 8 to $72 \%$, with the mass having a "putty-like" consistency. The organic content of the residue was estimated at between 12 and 40 liters; thus, a large amount of organic had been carried into the evaporator during the short time (about 90 minutes) that the system was operated.

\subsection{THE 1975 SAVANNAH RIVER DENITRATOR INCIDENT}

The second incident at Savannah River occurred on February 2, 1975 (Perkins et al. 1977 and Durant 1983) in the A-Line batch calciner (or denitrator). The uranium product from the PUREX process was first concentrated to about $400 \mathrm{~g} / \mathrm{L}$ (boiling point $=106^{\circ} \mathrm{C}$, specific gravity $=1.5$ ) in one of a set of evaporators and was further concentrated in a second set of "hydrate" evaporators to the approximate composition of uranyl nitrate hexahydrate (UNH) $\left[\mathrm{UO}_{2}\left(\mathrm{NO}_{3}\right)_{2} \cdot 6 \mathrm{H}_{2} \mathrm{O}\right]$ at about $1,200 \mathrm{~g} / \mathrm{L}$ (to a boiling point of $129^{\circ} \mathrm{C}$ ). The uranium content was at least $45 \mathrm{wt} \%$ but not more than $60 \mathrm{wt} \%$. Different reports state that the hydrate evaporator was heated with $<80$ psig steam to maintain a temperature $<160^{\circ} \mathrm{C}$ to prevent denitration or with $25 \mathrm{psig}$ steam with a maximum temperature of $129^{\circ} \mathrm{C}$ (Campbell and Mailen 1985).

Molten UNH was then transferred to a pot calciner and heated at a temperature greater than $129^{\circ} \mathrm{C}$ to dehydrate and denitrate it, yielding $\mathrm{UO}_{3}$. The denitrator incident occurred during this operation. Foaming was observed during the boil-off of $\mathrm{HNO}_{3}$ and water. To control the foaming, the molten unit was heated slowly at a temperature between 120 and $200^{\circ} \mathrm{C}$. At about $200^{\circ} \mathrm{C}$, foaming normally ceased and the denitration reaction began, becoming vigorous at about $220^{\circ} \mathrm{C}$. Heating continued to yield $\mathrm{UO}_{3}$.

The incident occurred during denitration of a series of non-routine batches that had presented a foaming problem. It should be noted that the melt could be observed, and that foaming during the heating process at a temperature below $200^{\circ} \mathrm{C}$ was not unusual. In this case, foaming occurred but nearly stopped; the skin temperature of the pot was then increased to $250^{\circ} \mathrm{C}$. Foaming stopped during the following 80 minutes, after which time the temperature was increased. About two minutes later, the incident began with the release of red-brown fumes. 
The operators took preventive actions for a few seconds before leaving the room as brown fumes filled the room. In several seconds, the contents of the calciner were forcibly ejected into the room and then an explosion occurred, causing minor injuries. This was followed by small and isolated fires that were easily contained. The explosion occurred outside the calciner and was caused by the ignition in air of organic vapors which resulted from the decomposition of the uranium nitrate-TBP complex. There was extensive damage to the room, but no damage to the denitrator.

Analytical data showed that the temperature of portions of the calciner contents was $<200^{\circ} \mathrm{C}$. It was estimated that the surface temperature of the pot may have been about $280^{\circ} \mathrm{C}$, and that the temperature of most of the denitrator contents was between 125 and $160^{\circ} \mathrm{C}$. Based on analyses of many samples, it was further estimated that the reaction involved decomposition of $\sim 190 \mathrm{~kg}$ of the $\mathrm{UO}_{2}\left(\mathrm{NO}_{3}\right)_{2} \cdot 2 \mathrm{TBP}$ adduct (containing $\sim 110 \mathrm{~kg}$ of TBP), which began at about $170^{\circ} \mathrm{C}$. Such a reaction would release $-500 \mathrm{M}^{3}$ of gas (at standard temperature and pressure) at a maximum rate of about $18 \mathrm{M}^{3} / \mathrm{s}$. The maximum energy release when this gas mixed with air and exploded was estimated to be $7 \times 10^{5} \mathrm{kcal}$.

It is clear that any TBP that accompanies the UNH and enters the calciner will undergo a chemical decomposition, because the calciner operates at a temperature high enough to initiate the reaction. The decomposition reaction occurs at temperatures between $130^{\circ} \mathrm{C}$ and $200^{\circ} \mathrm{C}$.

\subsection{THE RUSSIAN TOMSK INCIDENT}

On April 6, 1993 at Tomsk, Russia, a chemical explosion occurred in a nuclear fuel reprocessing plant (DOE 1993). The contents of a large process tank exploded causing substantial damage to the facility. Before the explosion, the tank was sequentially filled with the following approximate quantities:

- $4,000 \mathrm{~L}$ of heel solution (from the previous run) containing $30 \mathrm{~g} / \mathrm{L}$ uranium

- $19,500 \mathrm{~L}$ of $1.5 \mathrm{M}$ uranyl nitrate

- $500 \mathrm{~L}$ of degraded hydrocarbon solvent containing TBP

- $1,500 \mathrm{~L}$ of concentrated nitric acid.

Despite instructions to stir this mixture, operators apparently left this mixture in a multiphase layered configuration for several hours after adding the concentrated nitric acid. Workers subsequently noticed pressurization of the tank and brown fumes being emitted from the plant stack. About 13 minutes later, the tank ruptured, blew its lid and filled the plant with flammable organic vapors which subsequently ignited and blew out an exterior brick wall. Nearly all of the tank's contents emptied into the cell. 
During the investigation, the 2-inch vent valve for the tank was found half open. This accident was noteworthy and unique because it is the only recorded unheated process vessel explosion of its kind. 


\subsection{CONDITIONS AFFECTING RUNAWAY REACTIONS IN PROCESS VESSEIS}

\subsection{SEALED VERSUS VENTED SYSTEMS}

Oxidation of TBP by nitric acid or actinide nitrates in a vented system is less. hazardous than in a sealed system for the following reasons:

- The liquids are free to evaporate and in so doing are the principal means of removing heat from the system. This cools the reactants and prevents the reaction temperature from rising above the boiling points of the liquids.

- Reactant gases $\left(\mathrm{NO}_{2}\right)$ and liquids $\left(\mathrm{HNO}_{3}\right)$ are removed from the system, thereby preventing the release of all of the reaction energy potentially available.

Thus, the energy derived from oxidation of TBP in a vented system is limited by the following three factors:

- Nitric acid can vaporize and leave the system without reacting.

- The rate-controlling reactions do not permit more than a small fraction of the TBP to react before nitric acid is vaporized from the system.

- The resulting heat produced from the oxidation reaction will not heat the reaction mixture to temperatures required for a rapid reaction.

Oxidative reactions in a sealed system are more hazardous than in a vented system. Reactions in a sealed system proceed faster and yield more energy per TBP molecule for the following reasons:

- Solvents cannot evaporate and leave the system. Thus, heat removal is limited by relatively slow conduction and radiation mechanisms.

- Reactive gases cannot leave the system and therefore reactions tend to be complete and yield the maximum available energies.

- Since heat transfer is less efficient, the reaction temperature tends to rise to much higher values than in equivalent open systems.

- Reaction rates are increased by the high temperatures that are generated in a sealed system.

In a sealed system in which an uncontrolled reaction is initiated, the total energy is determined by the quantities of fuel and oxidizer in the system and not by the reaction rates. 
Therefore, assuming enough oxidant is present, it is expected that all of the reactants will react in a sealed system while only a small fraction are likely to react in a vented system.

\subsection{HEATING AND COOLING RATES}

The second factor, which is very important in determining whether a chemical explosion will occur (in a given piece of equipment), is the balance between the heating and cooling rates. Thermodynamic equations that predict the energy changes due to chemical reactions may be combined with kinetic rate data to predict the heating rate of a system. The cooling rate due to chemical reactions, phase changes, and thermal conduction must be also evaluated. It is therefore obvious that careful evaluation of the ability of a given process to dissipate heat to the environment must be made before the possibility of a chemical explosion is possible or probable. Equipment factors that hinder the cooling rate include the following:

- Sealed configurations that do not allow escape of vapors

- A small surface area to volume ratio

- Multiple shells within a process vessel

- External insulation around process vessels.

\subsection{SPECIFIC ACCIDENT SCENARIOS}

From the above discussion, possible violent chemical reaction scenarios include the following:

- Large tanks with small surface to volume ratios that are filled with reactive organics and contain enough oxidizers, such as nitrates, to generate high temperatures. Such tanks are especially dangerous when they are sealed.

- Heated process vessels that contain reactive oxidizers and organics and which are not designed to easily dissipate their heat to the environment. Such vessels are especially dangerous when they are sealed.

- Process vessels that contain organics which are internally nitrated or that contain large quantities of very concentrated oxidizers and organics. Again such vessels are especially dangerous when they are sealed. 


\subsection{EXPERIMENTAL}

\subsection{MATERIALS AND EQUIPMENT}

Reagent grade chemicals (tributyl phosphate, nitric acid, 1-butene, 1-butyl nitrate, 1-butanol, carbon tetrachloride, sodium nitrate, ammonium nitrate, and lithium nitrate) and distilled water were used in all the experimental work. Standard analyzed thorium nitrate (Standard \#19B19A\#3, $416.7 \mathrm{~g} / \mathrm{L} \mathrm{Th}$ ) and uranyl nitrate (Standard \#44B38, 111.23 g/L U) solutions in nitric acid were obtained from the Westinghouse Hanford Standards Laboratory. Bottled argon gas ( $99.999 \%$ argon, $1.9 \mathrm{ppm}$ air, $0.37 \mathrm{ppm} \mathrm{N}_{2}$ ) was used to provide an inert atmosphere above the samples during thermal analyses. Sources of reagent grade chemicals and their purity are shown in Table 4-1.

Table 4-1. Sources and Purity of Reagent Grade Chemicals Used in Experimental Work.

\begin{tabular}{llllll}
\multicolumn{1}{c}{ Name } & Formula & Manufacturer & \multicolumn{1}{c}{ Catalog } & \multicolumn{1}{c}{ No. } & \multicolumn{1}{c}{ Purity } \\
\hline 1-Butene & $\mathrm{C}_{4} \mathrm{H}_{8}$ & Aldrich & $29505-1$ & $99 \%$ \\
1-Butyl Nitrate & $\mathrm{C}_{4} \mathrm{H}_{9} \mathrm{ONO}_{2}$ & Pfaltz Bauer & $\mathrm{B30100}$ & b.p-136 \\
1-Butanol & $\mathrm{C}_{4} \mathrm{H}_{3} \mathrm{OH}$ & J. T. Baker & 9054 & $99.8 \%$ \\
Carbon Tetrachloride & $\mathrm{CCl}_{4}$ & Aldrich & 154717 & $99+\%$ \\
Tributyl Phosphate & $\left(\mathrm{C}_{4} \mathrm{H}_{9} \mathrm{O}\right)_{3} \mathrm{PO}$ & Aldrich & 240494 & $99+\%$ \\
Nitric Acid & $\mathrm{HNO}_{3}$ & J. T. Baker & $9606-04$ & Electronic Grade \\
Sodium Nitrate & $\mathrm{NaNO}_{3}$ & J. T. Baker & 3770 & $100.1 \%$ \\
Ammonium Nitrate & $\mathrm{NH}_{4} \mathrm{NO}_{3}$ & Aldrich & $6484-52-2$ & m.p. $169^{\circ} \mathrm{C}$ \\
Lithium Nitrate & $\mathrm{LiNO}_{3}$ & Allied & 1879 & $99.7 \%$ \\
\hline
\end{tabular}

The thermal analyzer used in these measurements was a Netzsch STA thermal analyzer (Model 409/429-403) coupled to a Balzers quadrupole mass spectrometer (Model QMS-420). This instrument is capable of simultaneous measurement of 1) weight changes in the sample (thermal gravimetry [TG]), 2) heat flow to or from the sample (differential thermal analysis [DTA]), and 3) the identity and quantity of gases evolved from the sample during heating. Heating or cooling rates and temperatures are pre-programmed with a computer that controls the operation of the equipment and receives all the thermal analysis and mass spectrometric data. The samples were contained in small platinum crucibles that were placed on an alumina sample holder, which was continuously weighed using a recording balance. 


\subsection{METHODS}

A number of thermal analyses were completed in which the following run parameters were varied: nitric acid/TBP ratio, thorium nitrate or uranyl nitrate concentrations, nitric acid concentration, heating rate, final temperature, cover gas flow rate, and sample size. A total of 35 runs were completed with sample sizes ranging from 53 to $232 \mathrm{mg}$. The samples were heated in platinum crucibles with pure argon gas flowing at a constant rate around the sample to avoid any reactions with air. Any oxygen in the sample chamber would complicate interpretation of the data and would not duplicate conditions expected in the process vessels. Mass spectral measurements of nitrogen gas (mass 28) in the sample chamber indicate that more than $99.9 \%$ of air is removed with the argon purge. Several isothermal runs at temperatures expected in the process vessels $\left(135^{\circ} \mathrm{C}, 145^{\circ} \mathrm{C}\right.$, and $\left.153^{\circ} \mathrm{C}\right)$ were also completed. Most samples were either composed of TBP that was previously equilibrated with concentrated nitric acid (single organic phase) or TBP with excess concentrated nitric acid (two phases). The use of concentrated nitric acid should yield a more reactive mixture than dilute acid, since more oxidizer is available to react. Several tests at lower nitric acid concentrations were completed to examine this variable. Thermal analyses of samples containing TBP with thorium or with uranyl nitrates were also completed.

The heat flow sensitivity of the instrument (DTA curves) was determined by running standard materials (ammonium nitrate and sodium nitrate) that have melting or phase transition points in the range of the exothermic and endothermic peaks observed for the $\mathrm{TBP}^{\mathrm{HNNO}} \mathrm{H}_{3}$ reactions. The endothermic peaks for the standard materials were integrated over the temperature ranges of $170^{\circ} \mathrm{C}$ to $192^{\circ} \mathrm{C}$ (for ammonium nitrate) and $270^{\circ} \mathrm{C}$ to $330^{\circ} \mathrm{C}$ (for sodium nitrate) using the packaged software program. The sensitivities $(0.722 \mu \mathrm{V} / \mathrm{mW}$ and $0.662 \mu \mathrm{V} / \mathrm{mW}$, respectively) were then entered into the program to convert the integrated exothermic peaks for the TBP-HNO ${ }_{3}$ and TBP-Th $\left(\mathrm{NO}_{3}\right)_{4}$ reactions to quantity of heat in J/g of sample. The J/g of sample was converted to J/g of TBP by dividing by ( $\mathrm{g}$ of TBP/g of sample).

Mass spectrometric data were obtained in two different forms: 1) Mass spectral scans of mass/z from 1 to 200 , requiring several seconds each, were obtained at three-minute intervals during heating and analyzed for gas mixtures at these times. 2) The intensities of up to $16 \mathrm{mass} / \mathrm{z}$ values that were characteristic of the gases identified in previous scans were measured continuously over the temperature range of interest. This allowed a continuous determination of the temperatures at which different reactions in the sample occurred.

The procedures used to operate the thermal analyzer-mass spectrometer were published by the instrument manufacturer, Netzsch, Incorporated of Exton, Pennsylvania. These were:

- Operating Instructions - Sofiware - Extenuation for Mass Spectrometer Coupling SW/QMS/311 for Computers HP Series 300, Issue III, 11/90, Netzsch-Geratebau GmbH, Wittelsbacherstrasse 42, P.O.B. 1460, D-8672, Selb, Germany 
- Software Handbook - SW/STA/311.001 - Simultaneous Thermal Analysis STA 409/429, Differential Thermal Analysis DTA 404, Issue II, 3/89, Netzsch-Geratebau GmbH, Wittelsbacherstrasse 42, P.O.B. 1460, D-8672, Selb, Germany. Calibration procedures for the thermal analyzer and mass spectrometer are also given in these instructions.

Accuracy and precision of the measurements reported in this document depend on uncertainties in mass, temperature, and DTA peak integration measurements. The specified accuracies of the thermogravimetric balance and the temperature measuring thermocouples are 1.25 micrograms and better than $1^{\circ} \mathrm{C}$, respectively. The temperature calibration was verified by heating standard compounds with known melting or transition temperatures. The balance accuracy was verified by heating standard compounds with known weight losses.

- The DTA peak integration measurement was calibrated using standard compounds with known enthalpy changes as described above. The estimated error (one sigma) for enthalpy measurements is about $12 \%$ based on errors observed for standard compounds (ammonium nitrate, lithium nitrate, and sodium nitrate). Mass spectral data were verified using standard materials such as 1-butane; 1-butanol, butyl nitrate, and air. 
WHC-EP-0737

This page intentionally left blank. 


\subsection{RESULTS AND DISCUSSION}

Reactions of TBP with nitric acid and with uranium and thorium nitrates were studied at elevated temperatures. In addition to these hydrolysis, dealkylation, and oxidation reactions, the thermal decomposition reactions of TBP were studied. The objectives were 1) to identify the reactions occurring, 2) to measure their rates, and 3) to measure enthalpy changes for the major reactions. This information is necessary to evaluate the potential for energetic reactions in process vessels in the Plutonium Finishing Plant.

\subsection{TRIBUTYL PHOSPHATE REACTIONS WITH NITRIC ACID}

The organic extractant used in the PFP to purify plutonium is a solution of $20 \%$ TBP (by volume) in carbon tetrachloride. This organic solvent is contacted with nitric acid in the extraction process. During contact, a significant amount of nitric acid and water is extracted into the organic phase. If the resulting solution is accidentally heated to the maximum temperatures of several existing heated process vessels, a series of phase changes and chemical reactions will occur. These events can be characterized by measuring thermal analysis curves for a sample of the solution as it is heated. For example, Figure 5-1 shows thermal analysis curves for a solution of TBP (20\% by volume) in carbon tetrachloride that was equilibrated with concentrated nitric acid. The thermogravimetric (TG) curve measures mass loss from the sample over the temperature range, $20^{\circ} \mathrm{C}$ to $360^{\circ} \mathrm{C}$. The differential thermal analysis (DTA) curve measures heat flow from the sample (for an exothermic process) and to the sample (for an endothermic process). Mass spectrometric data (not shown) identify gases evolved during each thermal event over the same temperature range.

The TG curve in Figure 5-1 shows a large amount of sample weight loss at temperatures of $20^{\circ} \mathrm{C}$ to $100^{\circ} \mathrm{C}$ that is due to evaporation and boiling of the carbon tetrachloride. A corresponding endotherm is observed in the DTA curve since this phase change requires absorption of heat by the sample. Some water is also probably lost from the sample during the evaporation since a binary azeotrope $\left(95.9 \% \mathrm{CCl}_{4}\right.$ with a boiling point of $66^{\circ} \mathrm{C}$ ) is known to form with water-carbon tetrachloride mixtures. At about $140^{\circ} \mathrm{C}$ an exothermic reaction is observed that is probably caused by oxidation of the TBP by nitric acid. This reaction continues until essentially all of the nitric acid is removed from the organic solution by vaporization or reaction at about $175^{\circ} \mathrm{C}$. The oxidation reaction is quite slow at the these temperatures and only a small amount of the TBP is reacted before the nitric acid oxidant is evolved from the solution. The rate of oxidation is controlled by either the hydrolysis of TBP or by dealkylation of TBP by nitric acid. The hydrolysis product (1-butanol) and dealkylation product (1-butyl nitrate) are much more reactive toward oxidizers, such as nitric acid, than is TBP. 
Figure 5-1. TG (..) and DTA $\circlearrowright$ Curves for $231.7 \mathrm{mg}$ of 20\% TBP in Carbon Tetrachloride Saturated with Concentrated Nitric Acid (31.4 mg TBP, $191 \mathrm{mg} \mathrm{CCl}$, and 9.3 $\mathrm{mg} \mathrm{HNO}+\mathrm{H}_{2} \mathrm{O}$ ). Atmosphere $=$ Argon, Flow Rate $=100 \mathrm{cc} / \mathrm{min}$, Heating Rate $=3.0$ C $/$ min.

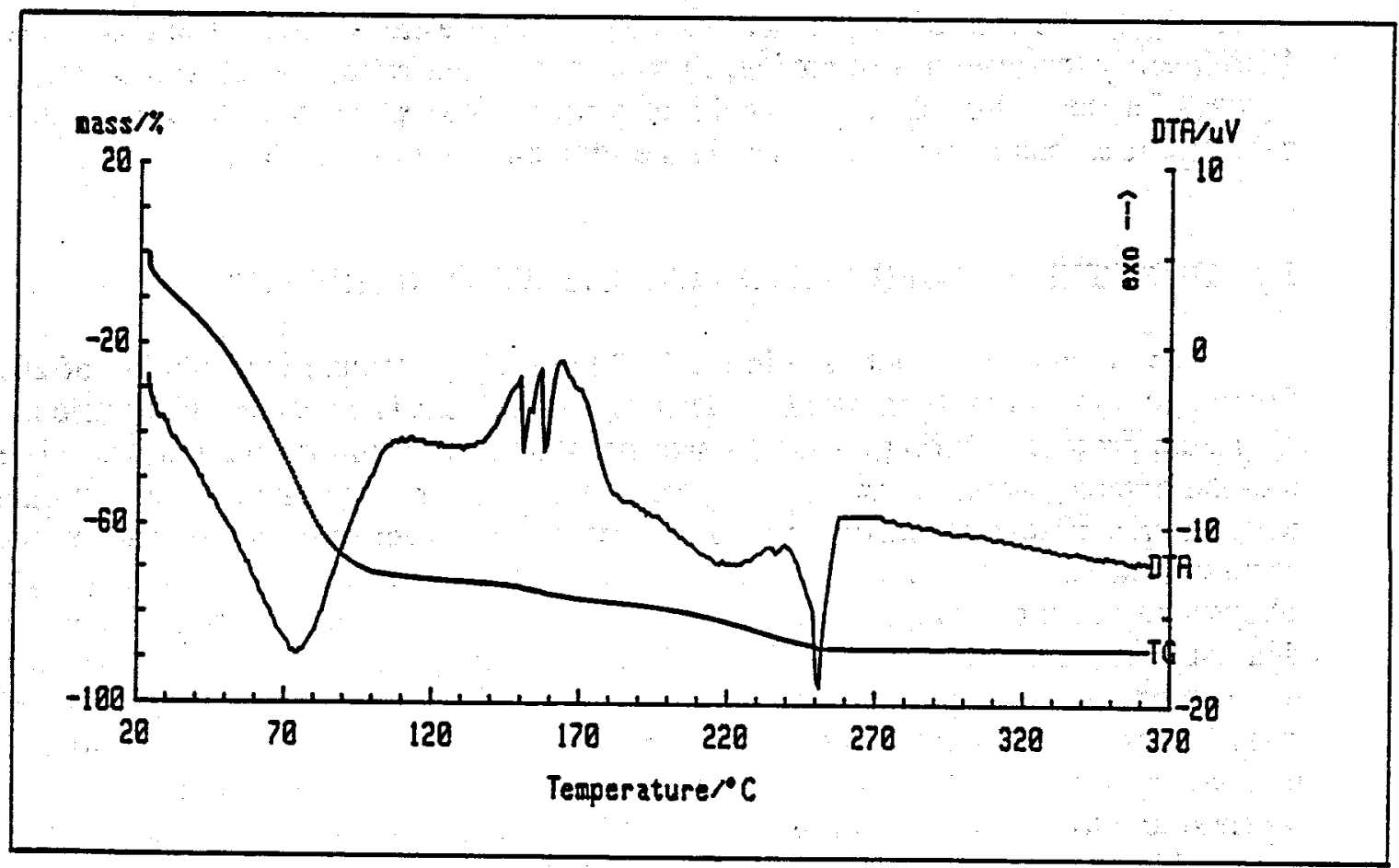

The initial reactions are thought to be:

$$
\begin{array}{r}
\left(\mathrm{C}_{4} \mathrm{H}_{9} \mathrm{O}\right)_{3} \mathrm{PO}+\mathrm{H}_{2} \mathrm{O} \rightarrow\left(\mathrm{C}_{4} \mathrm{H}_{9} \mathrm{O}_{2} \mathrm{POOH}+\mathrm{C}_{4} \mathrm{H}_{9} \mathrm{OH}\right. \\
\mathrm{C}_{4} \mathrm{H}_{9} \mathrm{OH}+\mathrm{HNO}_{3} \rightarrow \mathrm{C}_{4} \mathrm{H}_{9} \mathrm{ONO}_{2}+\mathrm{H}_{2} \mathrm{O} \\
\text { or }\left(\mathrm{C}_{4} \mathrm{H}_{9} \mathrm{O}\right)_{3} \mathrm{PO}+\mathrm{HNO}_{3} \rightarrow 3\left(\mathrm{C}_{4} \mathrm{H}_{9} \mathrm{O}_{2} \mathrm{POOH}+\mathrm{C}_{4} \mathrm{H}_{9} \mathrm{ONO}_{2}\right.
\end{array}
$$

The butyl nitrate that is formed initially by either reaction is unstable in acid solution and rapidly decomposes to oxidized intermediates (aldehydes, carboxylic acids, and alcohols). The oxidation may continue to carbon dioxide, probably through free radical mechanisms. An overall reaction is:

$$
\mathrm{C}_{4} \mathrm{H}_{9} \mathrm{ONO}_{2}+7 \mathrm{HNO}_{3} \rightarrow 4 \mathrm{CO}_{2}+8 \mathrm{NO}+8 \mathrm{H}_{2} \mathrm{O}
$$


Although a published paper ( $\mathrm{L} i$ et al. 1992) claims that the oxidation of butanol stops after propanoic acid is formed, no mass spectrometric evidence was found in the present study for the existence of carboxylic acids in the mixtures. If present, they should produce a prominent peak at mass $60\left(\mathrm{CH}_{2} \mathrm{COOH}^{+}\right)$. This peak was not observed in any of the mass spectra. After the oxidation reaction is complete, the sample weight loss continued as the temperature increased and the DTA curve shows that an endothermic reaction occurs up to about $250^{\circ} \mathrm{C}$. This reaction will be shown later to be the pyrolysis or thermal degradation of TBP. Mass spectrometric analyses of the gaseous reaction products show that 1-butene and water are the major gaseous products of the reaction. The overall reaction is as follows:

$$
2\left(\mathrm{C}_{4} \mathrm{H}_{9} \mathrm{O}\right)_{3} \mathrm{PO} \rightarrow 6 \mathrm{C}_{4} \mathrm{H}_{8}+\mathrm{H}_{2} \mathrm{O}+\mathrm{H}_{4} \mathrm{P}_{2} \mathrm{O}_{7} .
$$

This reaction can seriously affect safety analyses of the processing equipment because butene is highly flammable in air and can be explosive when mixed with air. Above $250^{\circ} \mathrm{C}$ no further reaction is observed and the sample weight remains constant at about $12 \%$ of the original weight.

Since the carbon tetrachloride will evaporate at low temperatures before any significant reactions occur, additional measurements were made without the presence of carbon tetrachloride. These measurements were made to determine the effects of important variables on the reactions of nitric acid with TBP. These variables include nitric acid concentration, nitric acid/TBP ratios, and heating rate. The effects of the presence of air in the vapor space above the mixtures and the presence of butanol in the mixtures were also examined. The reaction enthalpy changes and the rates of reaction were measured in some of these tests. Continuous mass spectrometric analysis of the gaseous reaction products allowed identification of the reactions occurring in these mixtures.

Mass spectrometric data were used to identify gaseous reaction products and vaporized compounds from heated nitric acid-TBP mixtures. For example, the offgases were identified during heating of a 1:1 mixture (by volume) of concentrated nitric acid (15.7 MD and TBP that was previously saturated with concentrated nitric acid. The TG and DTA curves for this mixture over a temperature range of $20^{\circ} \mathrm{C}$ to $360^{\circ} \mathrm{C}$ are shown in Figure 5-2. Mass intensity curves were obtained simultaneously for sixteen different mass/charge ratios during this run. Six of these curves (for masses 12, 28, 30, 44, 46, and 56) are shown in Figure 5-3. A comparison of curves for mass $12\left(\mathrm{C}^{+}\right)$, mass $44\left(\mathrm{CO}_{2}^{+}, \mathrm{N}_{2} \mathrm{O}^{+}\right.$, or $\left.\mathrm{C}_{3} \mathrm{H}_{8}^{+}\right)$, and mass 56 $\left(\mathrm{C}_{4} \mathrm{H}_{8}{ }^{+}\right)$in part $\mathrm{A}$ of Figure 5-3 indicates that oxidized carbon $\left(\mathrm{CO}_{2}\right.$ or $\left.\mathrm{CO}\right)$ is evolved in the $125^{\circ} \mathrm{C}$ to $175^{\circ} \mathrm{C}$ temperature range. The mass 56 curve shows that 1-butene is evolved in very low concentrations until a temperature of about $160^{\circ} \mathrm{C}$ is reached when its concentration increases until a sharp peak concentration is reached at about $253^{\circ} \mathrm{C}$. The curves for mass $28\left(\mathrm{~N}_{2}^{+}, \mathrm{CO}^{+}\right.$, or $\left.\mathrm{C}_{2} \mathrm{H}_{4}^{+}\right)$, mass $30\left(\mathrm{NO}^{+}\right.$or $\left.\mathrm{C}_{2} \mathrm{H}_{6}{ }^{+}\right)$and mass $46\left(\mathrm{NO}_{2}{ }^{+}\right.$or $\left.\mathrm{C}_{2} \mathrm{H}_{5} \mathrm{OH}^{+}\right)$in part B of Figure 5-3 show that nitric acid is evaporated over $125^{\circ} \mathrm{C}$ to $175^{\circ} \mathrm{C}$. The reduced nitrogen from TBP oxidation with nitric acid was identified as $\mathrm{NO}$ and $\mathrm{N}_{2}$. Mass intensity curves for masses $18\left(\mathrm{H}_{2} \mathrm{O}^{+}\right), 27\left(\mathrm{C}_{2} \mathrm{H}_{3}{ }^{+}\right)$, and $29\left(\mathrm{C}_{2} \mathrm{H}_{5}^{+}\right)$in Figure 5-4 show that large 
amounts of water are evolved between $125^{\circ} \mathrm{C}$ and $180^{\circ} \mathrm{C}$ with a smaller spike observed at about $253^{\circ} \mathrm{C}$. The mass 27 and 29 curves have the same shape as the butene parent peak (mass 56) and are, therefore, 1-butene fragment ions.

Figure 5-2. TG (..) and DTA ( Curves for $138.0 \mathrm{mg}$ of Mixture of TBP (Previously Saturated with Concentrated Nitric Acid) and Concentrated Nitric Acid (66.9 mg TBP, and $71.1 \mathrm{mg} \mathrm{BNO}{ }_{3}+\mathrm{H}_{2} \mathrm{O}$ ). Atmosphere = Argon, Flow Rate $=100 \mathrm{cc} / \mathrm{min}$, Heating Rate $=$ $3.0^{\circ} \mathrm{C} / \mathrm{min}$.

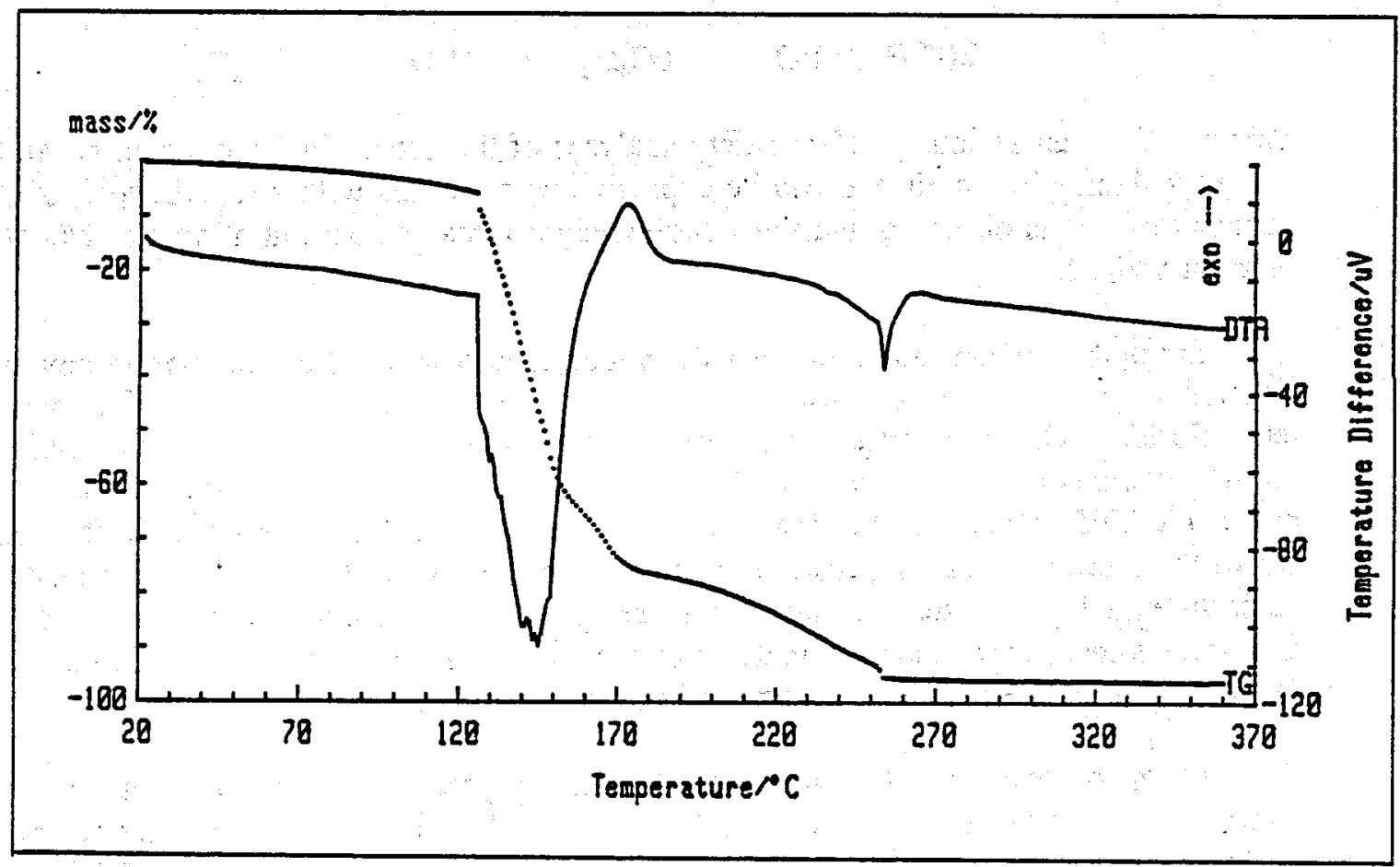

Additional proof of gaseous product identification was obtained by measuring mass spectra of known compounds and comparing these to spectra of gases evolved from the nitric acid-TBP mixtures. The spectrum of gas evolved from pure TBP at $251^{\circ} \mathrm{C}$ is compared to the spectrum of pure 1-butene in Figure 5-5. The spectra are essentially identical, except for artifact peaks at masses 20,28 , and 40 in the TBP spectrum due to imperfect background spectrum subtraction. These data positively identify 1-butene to be the major pyrolysis product of TBP. Figure 5-6 compares spectra of gases evolved from TBP at $144^{\circ} \mathrm{C}$ (the TBP was saturated previously with concentrated nitric acid) with pure concentrated nitric acid. The spectra are similar except for the presence of small peaks at masses 12, 26, 27, $29,41,42,43,55$, and 56 in the TBP (saturated with concentrated $\mathrm{HNO}_{3}$ ) spectrum due to butene ion fragments. The mass intensities for water ions are greater in the pure nitric acid spectrum, indicating relatively more water is present than in the TBP phase equilibrated with concentrated nitric acid. 
Figure 5-3. Mass Intensity Curves During Thermal Analysis of $138 \mathrm{mg}$ of Mixture of TBP (Previously Saturated with Concentrated Nitric Acid) and Concentrated Nitric Acid (66.9 mg $\mathrm{TBP}$, and $71.1 \mathrm{mg} \mathrm{HNO}_{3}+\mathrm{H}_{2} \mathrm{O}$ ). Atmosphere $=$ Argon, Flow Rate $=100 \mathrm{cc} / \mathrm{min}$, Heating Rate $=3.0^{\circ} \mathrm{C} / \mathrm{min}$. (A) Mass $12 \bigcup$, Mass $44(.$.$) , and Mass 56(-)$. (B) Mass $28($, Mass $30(.$.$) , and Mass 46 \sqcup$.

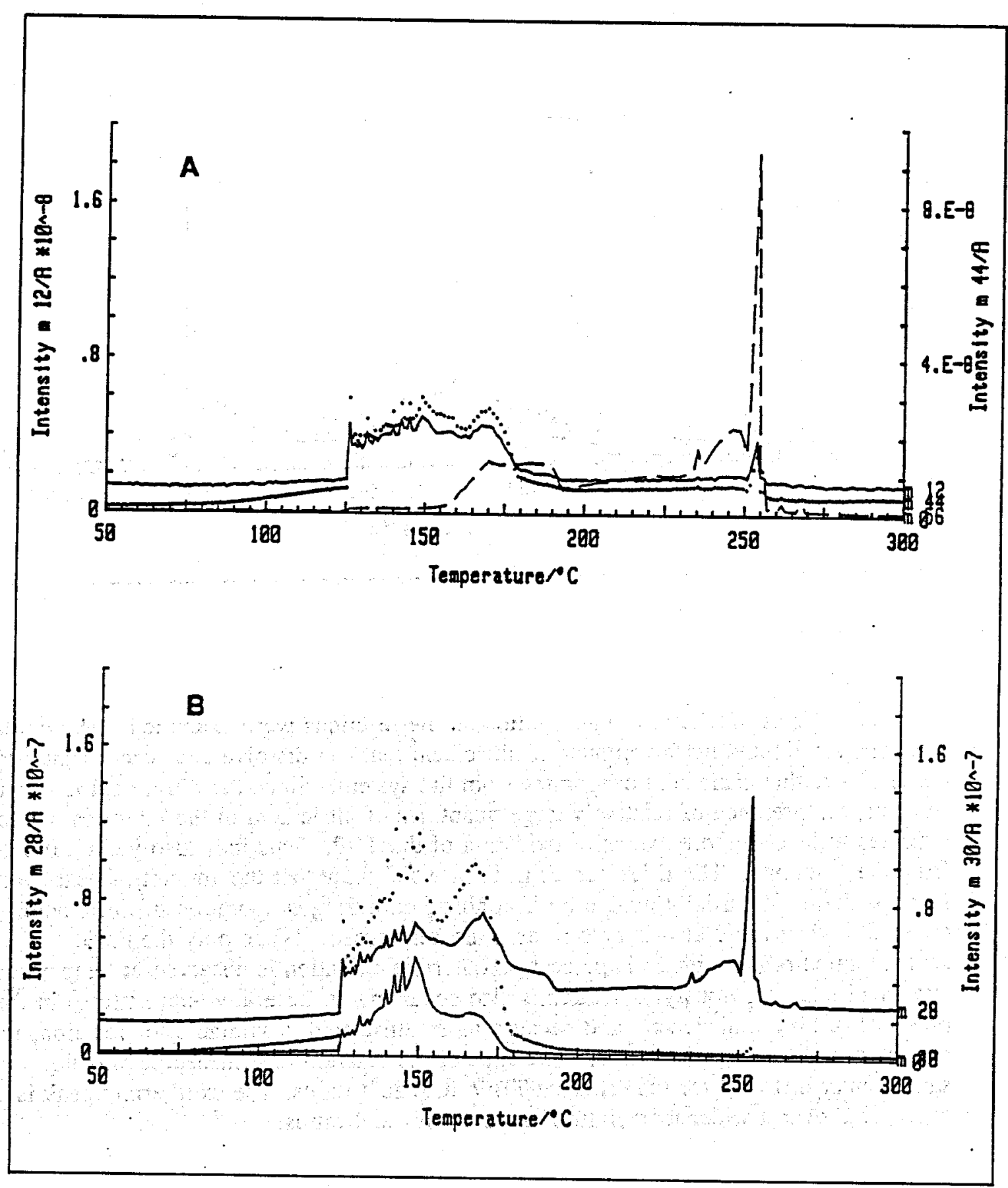


Figure 5-4. Mass Intensity Curves During Thermal Analysis of $138 \mathrm{mg}$ of Mixture of TBP (Previously Saturated with Concentrated Nitric Acid) and Concentrated Nitric Acid (66.9 mg

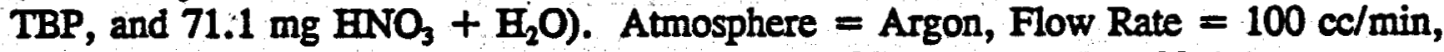
Heating Rate $=3.0^{\circ} \mathrm{C} / \mathrm{min}$. Mass $18($, Mass $27(.$.$) , and Mass 29(-)$.

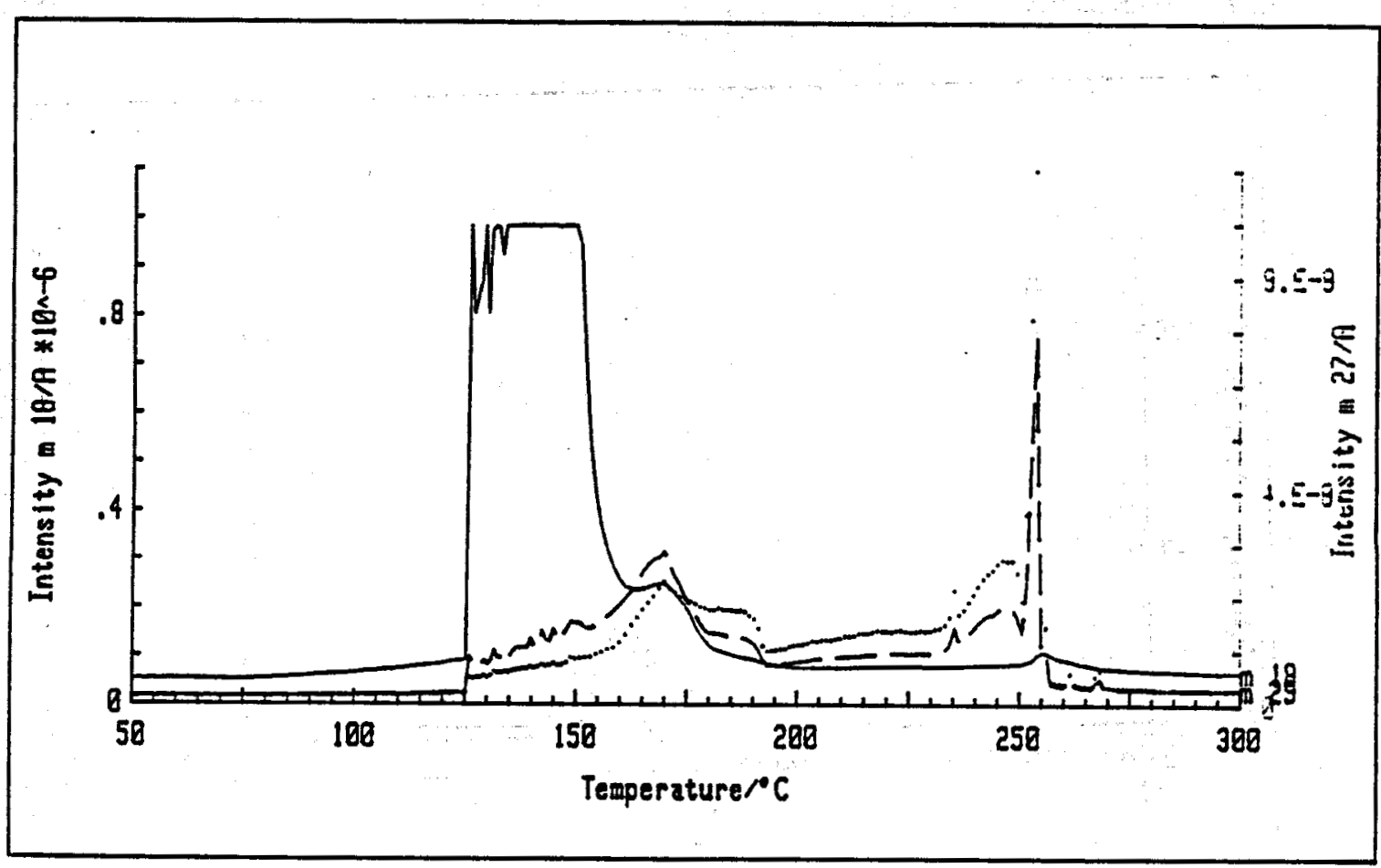

The effects of TBP/nitric acid ratios on the reactions were examined. The oxidation reactions are limited by the amount of nitric acid that can dissolve and react in the organic phase before this nitric acid evaporates from the system. Since the nitric acid is the limiting reactant, the presence of relatively large quantities of nitric acid in the mixtures would be expected to lead to more extensive oxidation of the TBP. This may also yield more heat from the reactions. The DTA curves in Figure 5-7 show that the amount of heat evolved from oxidation is partially hidden by heat absorbed during evaporation of nitric acid, especially when nitric acid is present as a separate phase. When only the nitric acid-saturated organic phase is present, exothermic oxidation is observed at temperatures as low as $110^{\circ} \mathrm{C}$. Obviously, oxidation is also occurring at these low temperatures in the presence of excess nitric acid and because more nitric acid is available for reaction, the oxidation will be more extensive. The exothermic reaction heat measured was not significantly different for the different TBP/nitric acid ratios. The exothermic peak is observable over 2 wider temperature range at low acid ratios. 
Figure 5-5. Mass Spectra of Pure TBP Heated to $251^{\circ} \mathrm{C}(\mathrm{A})$ and Pure 1-Butene Reference Gas (B).

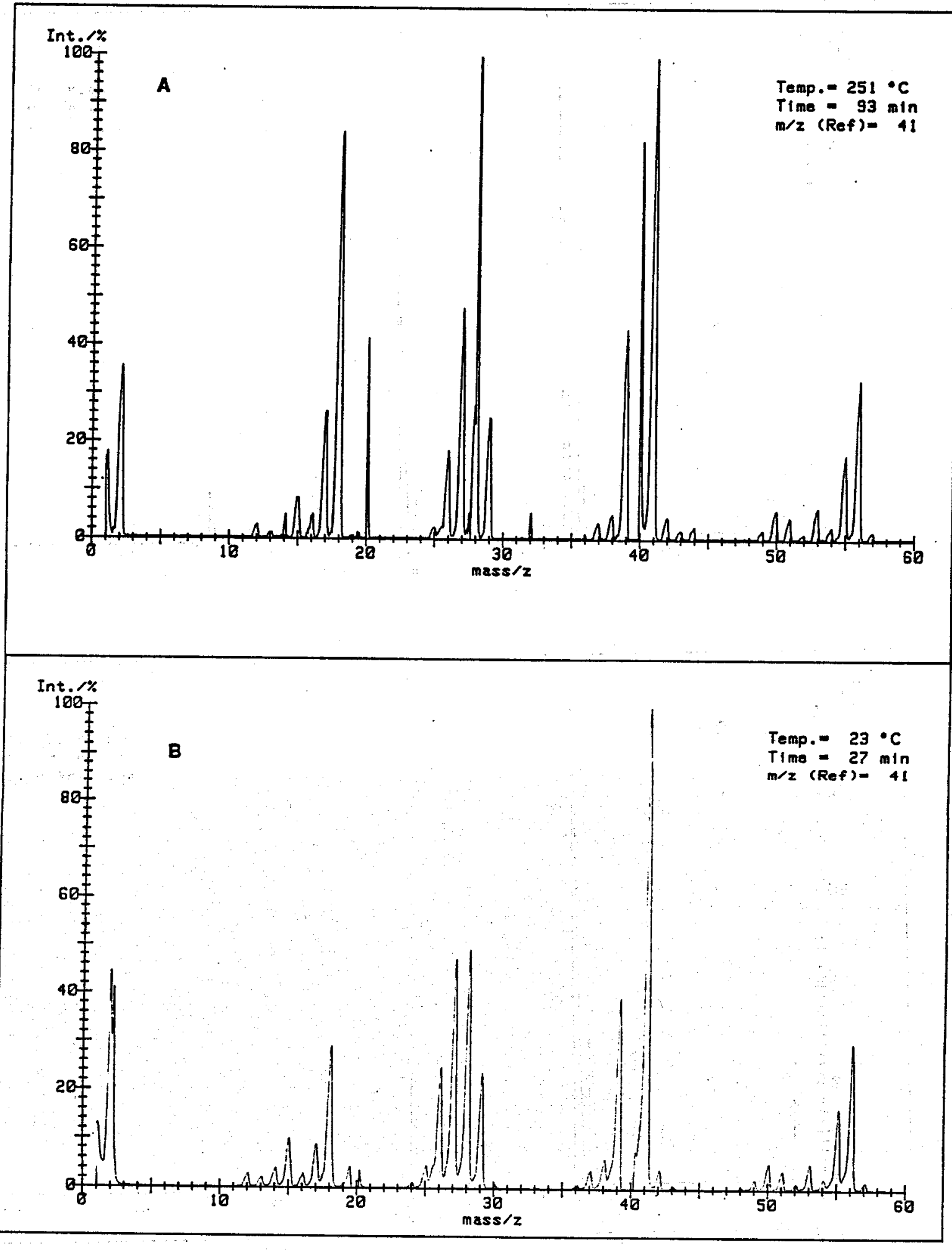


Figure 5-6. Mass Spectra of TBP Saturated with Concentrated Nitric Acid Heated to $144^{\circ} \mathrm{C}$ (A) and Pure Concentrated Nitric Acid Reference Liquid at $128^{\circ} \mathrm{C}$ (B).

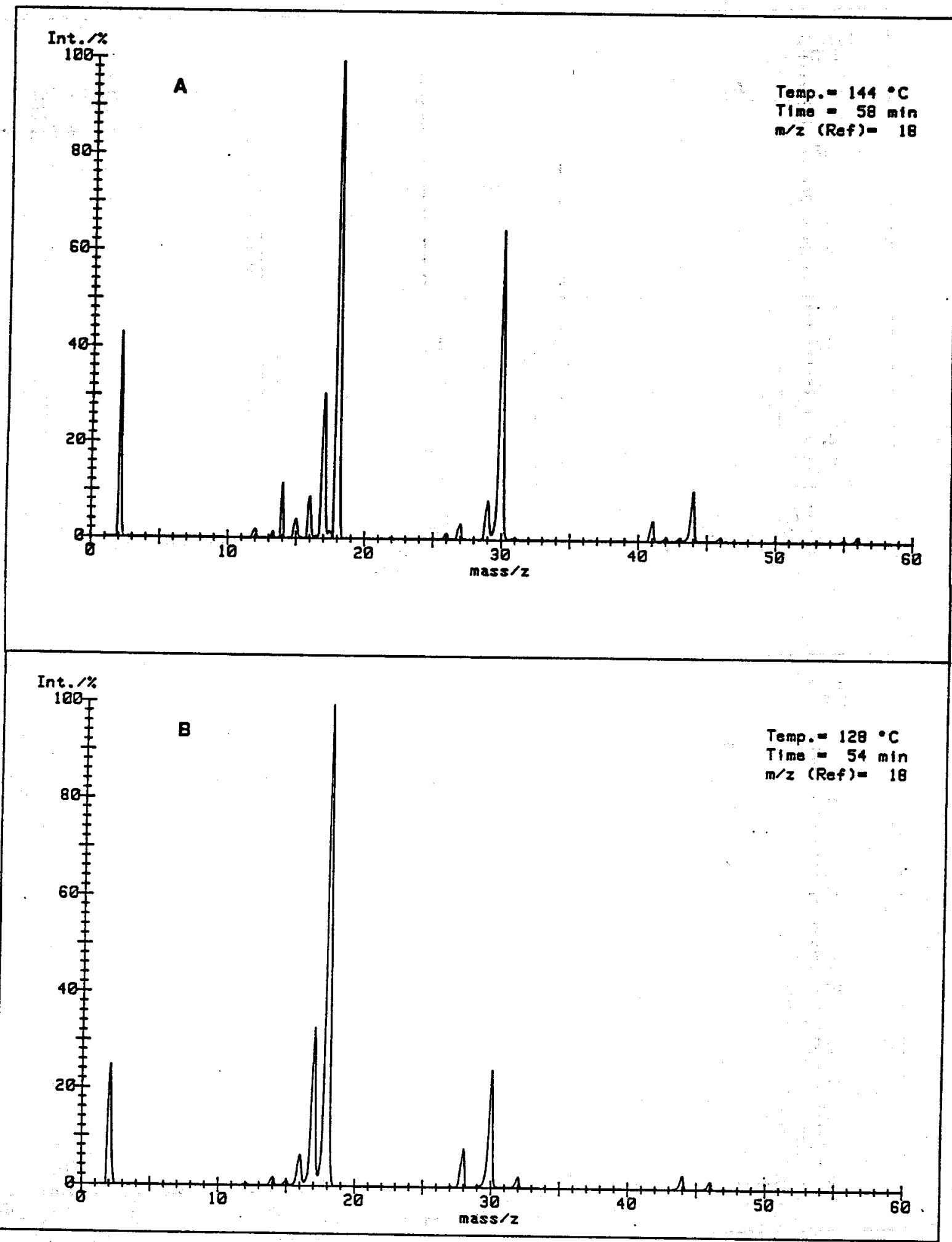


Figure 5-7. Comparison of DTA Curves for Mixtures Containing Different Ratios of TBP/Nitric Acid. $\bigcup 39.9 \mathrm{mg}$ TBP + $14.8 \mathrm{mg} \mathrm{BNO}{ }_{3}$, (..) $33.1 \mathrm{mg}$ TBP + $104.9 \mathrm{mg}$ $\mathrm{HNO}_{3}$, and $(-) 29.9 \mathrm{mg} \mathrm{TBP}+169.6 \mathrm{mg} \mathrm{HNO}$. Atmosphere $=$ Argon, Flow Rate $=100$ $\mathrm{cc} / \mathrm{min}$, Heating Rate $=3.0^{\circ} \mathrm{C} / \mathrm{min}$.

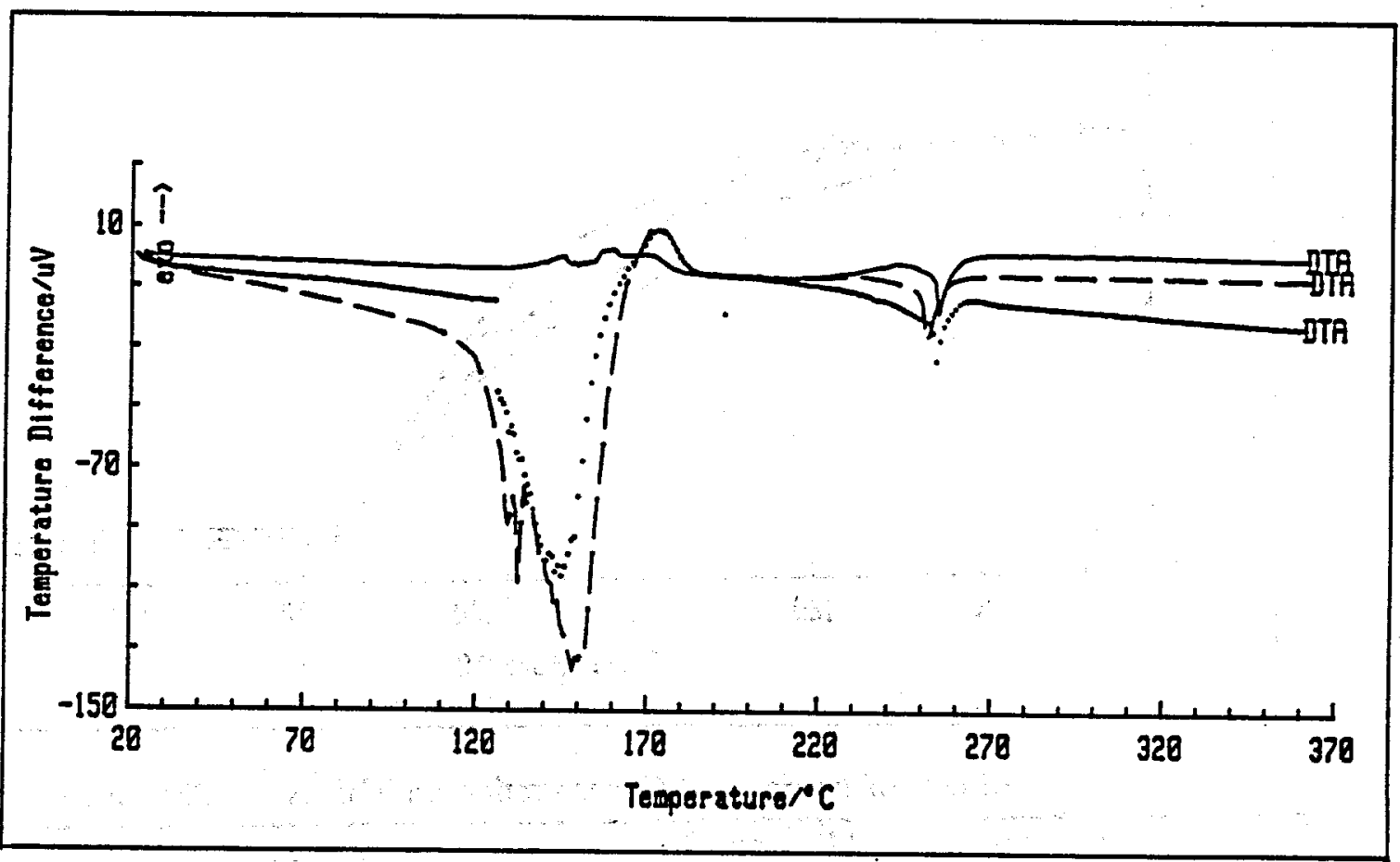

The effects of nitric acid concentration on TBP-nitric acid reactions were examined. Several $\mathrm{mL}$ portions of pure TBP were equilibrated with large excesses of nitric acid solutions at 15.7, 12.0, 8.0, or $3.0 \mathrm{M}$ nitric acid.

The organic phases saturated with these nitric acid solutions were analyzed to determine 1) the net amount of heat produced from the oxidation reaction, 2) the lowest observable reaction temperature, and 3) the amount of nitric acid and water extracted into the TBP. The TG curves for the saturated organic phases (Figure 5-8) show that, as expected, less water and nitric acid are extracted as the aqueous nitric acid concentration decreases. The sample weight losses due to evaporation and reaction of the water and nitric acid occur at temperatures from about $40^{\circ} \mathrm{C}$ to $170^{\circ} \mathrm{C}$. The measured net heat evolved, initial reaction temperatures, and the amounts of nitric acid and water extracted are given in Table 5-1. The amount of heat evolved decreases only slightly as nitric acid concentrations are lowered. The smaller oxidation heats are partially balanced by lower heats of vaporization because less 
Figure 5-8. Comparison of TG Curves for TBP Equilibrated with Various Aqueous Concentrations of Nitric Acid. $\bigcup 15.7 \mathrm{M} \mathrm{HNO}_{3},(.) .12.0 \mathrm{M} \mathrm{HNO}_{3},(-) 8.0 \mathrm{M} \mathrm{HNO}$, and (..) $3.0 \mathrm{M} \mathrm{HNO}_{3}$.

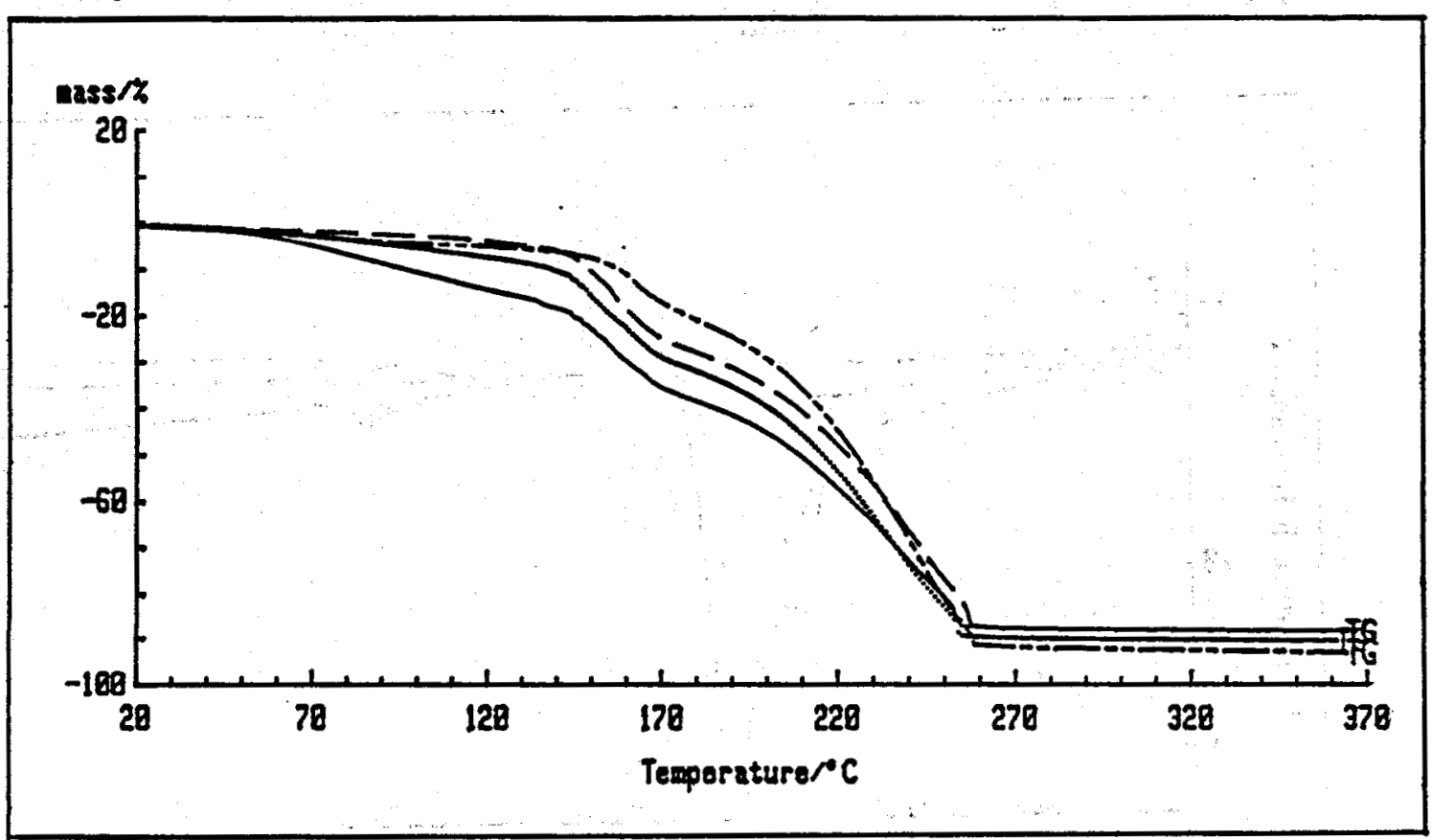

Table 5-1. Effects of Nitric Acid Concentration on TBP-Nitric Acid Reactions.

\begin{tabular}{|c|c|c|c|c|c|}
\hline \multirow[b]{2}{*}{$\begin{array}{c}\text { Aqueous } \\
{\left[\mathrm{HNO}_{3}\right], \mathrm{M}}\end{array}$} & \multirow{2}{*}{$\begin{array}{c}\text { Initial } \\
\text { Reaction } \\
\text { Temperature, } \\
{ }^{\circ} \mathrm{C}\end{array}$} & \multirow{2}{*}{$\begin{array}{l}\text { Measured } \\
\text { Heat } \\
\text { Evolved, } \\
\text { J/g TBP }\end{array}$} & \multicolumn{3}{|c|}{ Equilibrated Organic Composition } \\
\hline & & & $\begin{array}{c}\mathrm{gHNO}_{3} / \mathrm{g} \\
\mathrm{TBP}\end{array}$ & $\begin{array}{l}\mathrm{g} \mathrm{H}_{2} \mathrm{O} / \mathrm{g} \\
\mathrm{TBP}\end{array}$ & Measured $\%\left(\mathrm{HNO}_{3}+\mathrm{H}_{2} \mathrm{O}\right)$ \\
\hline 15.7 & 125 & 109 & 0.41 & 0.046 & $\overline{35}$ \\
\hline 12.0 & 128 & 115 & 0.33 & 0.028 & 29 \\
\hline 8.0 & 133 & $\overline{83}$ & 0.26 & 0.024 & 24 \\
\hline 3.0 & 140 & 89 & 0.15 & 0.042 & 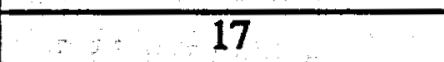 \\
\hline
\end{tabular}

nitric acid and water are present initially at lower aqueous acid concentrations. As expected, the initial temperatures of oxidation increase as the acid concentrations are lowered.

The presence of air in contact with the reacting mixtures could be significant if oxygen can react with TBP or any reaction products. Two thermal analysis measurements were made with all run parameters the same, except that flowing air was used as the cover gas in the first run and flowing argon in the second. The DTA curves for these runs are compared in Figure 5-9. The curves are similar up to a temperature of about $220^{\circ} \mathrm{C}$. At temperatures above $220^{\circ} \mathrm{C}$ the sample run in air shows a more exothermic tendency than the sample run 
Figure 5-9. Effect of Air Atmosphere on DTA (A) and TG (B) Curves for TBP Saturated

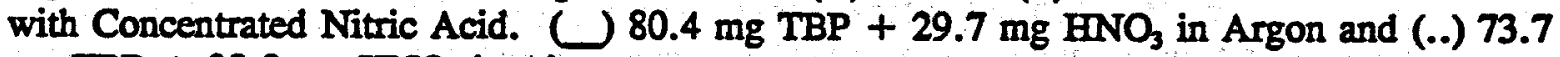
$\mathrm{mg} \mathrm{TBP}+38.0 \mathrm{mg} \mathrm{HNO}$ in Air.

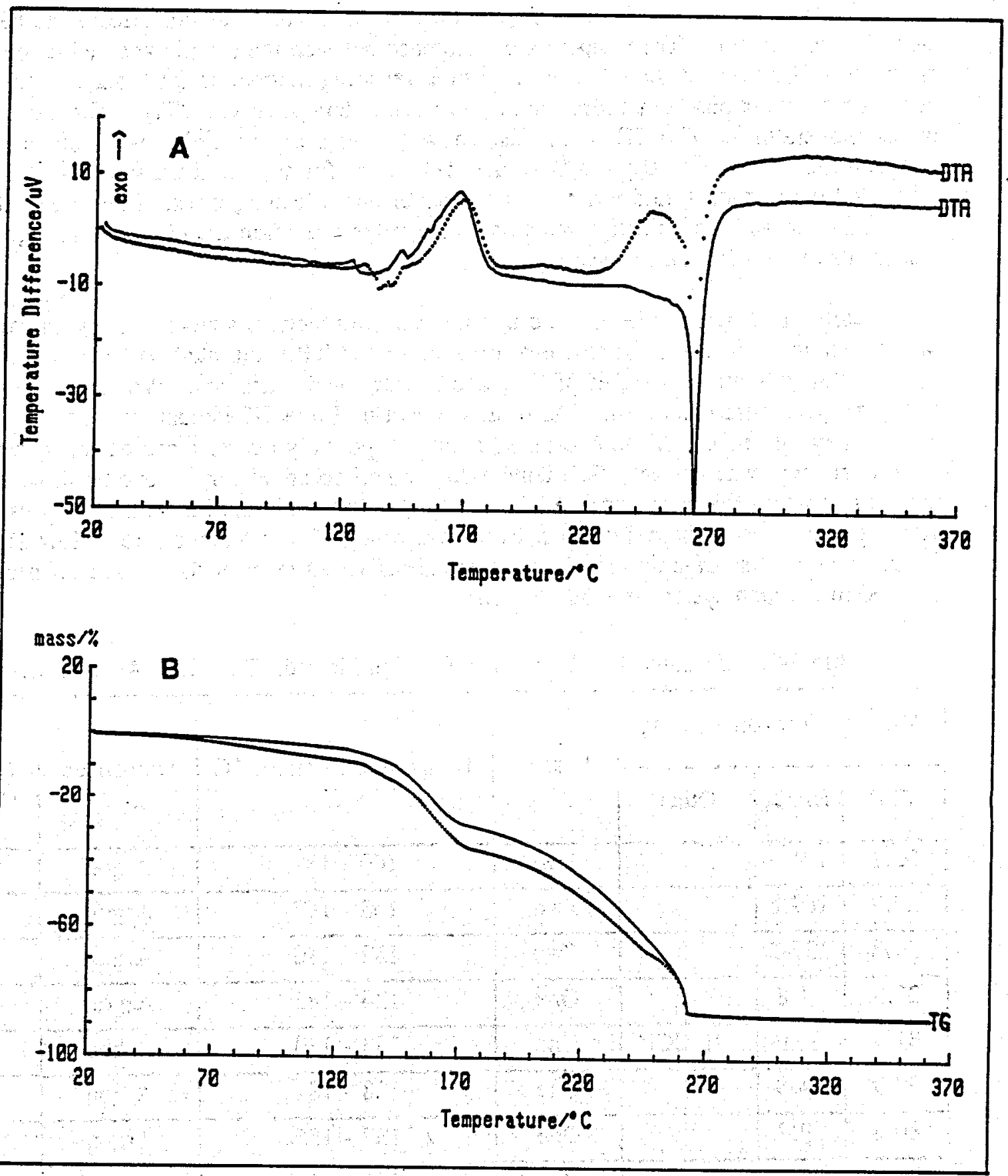


under argon. Apparently, air oxidizes a compound in the sample to produce heat. Not much air should be present in the process vessels because it will be displaced as carbon tetrachloride, water and nitric acid are vaporized during heat-up.

Heating rate will affect the reactions because of thermal transfer effects and because of slow reaction kinetics. The temperature difference between the sample and reference crucibles will be less at the lower heating rate, resulting in smaller DTA peaks. Also, at low heating rates reactions have more time to go to completion, so the DTA peaks are shifted to lower temperatures. The TG curves also show greater sample weight loss at lower temperatures. Figure 5-10 gives DTA and TG curves for similar sized samples of TBP (saturated with concentrated nitric acid) at four different heating rates. The size of the DTA peaks increase and the oxidation reaction and pyrolysis reaction are complete at higher temperatures with increasing heating rates.

Exothermic reaction heats were measured during thermal analysis of several runs. Measurements were made for single-phase solutions of TBP saturated with concentrated nitric acid and for two-phase mixtures of TBP and concentrated nitric acid. Various ratios of TBP and nitric acid were examined. The results shown in Table 5-2 indicate that reaction heats were somewhat higher for the two-phase mixtures, possibly due to more extensive reaction as more nitric acid was present. The temperature range observed for the exotherm was smaller for the two-phase mixtures because of the strong endothermic boiling of the aqueous phase nitric acid solution. The oxidation reaction was observed at a temperature as low as $126^{\circ} \mathrm{C}$ for the single-phase organic reactions. A conservative estimate of the amount of heat evolved in an open system is $-150 \mathrm{~J} / \mathrm{g}$ TBP.

Table 5-2. Measured Net Heat Evolved from Heated TBP-Nitric Acid Mixtures.

\begin{tabular}{|c|c|c|c|c|c|c|}
\hline \multicolumn{2}{|c|}{ Mixture Components, mg } & \multirow{2}{*}{ Phases } & Temperature Range, ${ }^{\circ} \mathrm{C}$ & Atmosphere & $\begin{array}{c}\text { Measured } \\
\text { Heat }\end{array}$ \\
\cline { 1 - 4 } TBP & $\mathrm{HNO}_{3}$ & Other & & & & $\begin{array}{c}\text { Joules/g } \\
\text { TBP }\end{array}$ \\
\hline 33.1 & 104.9 & & Two & $160-187$ & Argon & -147 \\
\hline 29.9 & 169.6 & & Two & $163-187$ & Argon & -140 \\
\hline 59.8 & 127.2 & & Two & $152-180$ & Argon & -98 \\
\hline 37.9 & 14.8 & & One & $126-182$ & Argon & -117 \\
\hline 31.4 & 9.3 & 191 CCl4 & One & $133-180$ & Argon & -137 \\
\hline 39.9 & 14.8 & & One & $128-181$ & Argon & -127 \\
\hline 80.4 & 29.7 & & One & $137-185$ & Argon & -101 \\
\hline 73.7 & 38.0 & & One & $145-185$ & Air & -70 \\
\hline
\end{tabular}


Figure 5-10. Effect of Heating Rate on DTA (A) and TG (B) Curves for TBP Saturated with Concentrated Nitric Acid. $37.6 \mathrm{mg}$ TBP $+20.3 \mathrm{mg} \mathrm{HNO}, 5^{\circ} \mathrm{C} / \mathrm{min} ;(.) .39.9 \mathrm{mg}$ $\mathrm{TBP}+14.8 \mathrm{mg} \mathrm{HNO}, 3{ }^{\circ} \mathrm{C} / \mathrm{min} ;(-) 38.9 \mathrm{mg} \mathrm{TBP}+21.9 \mathrm{mg} \mathrm{HNO}, 2^{\circ} \mathrm{C} / \mathrm{min} ;$ and (.) $37.6 \mathrm{mg} \mathrm{TBP}+21.1 \mathrm{mg} \mathrm{HNO}_{3}, 1^{\circ} \mathrm{C} / \mathrm{min}$.

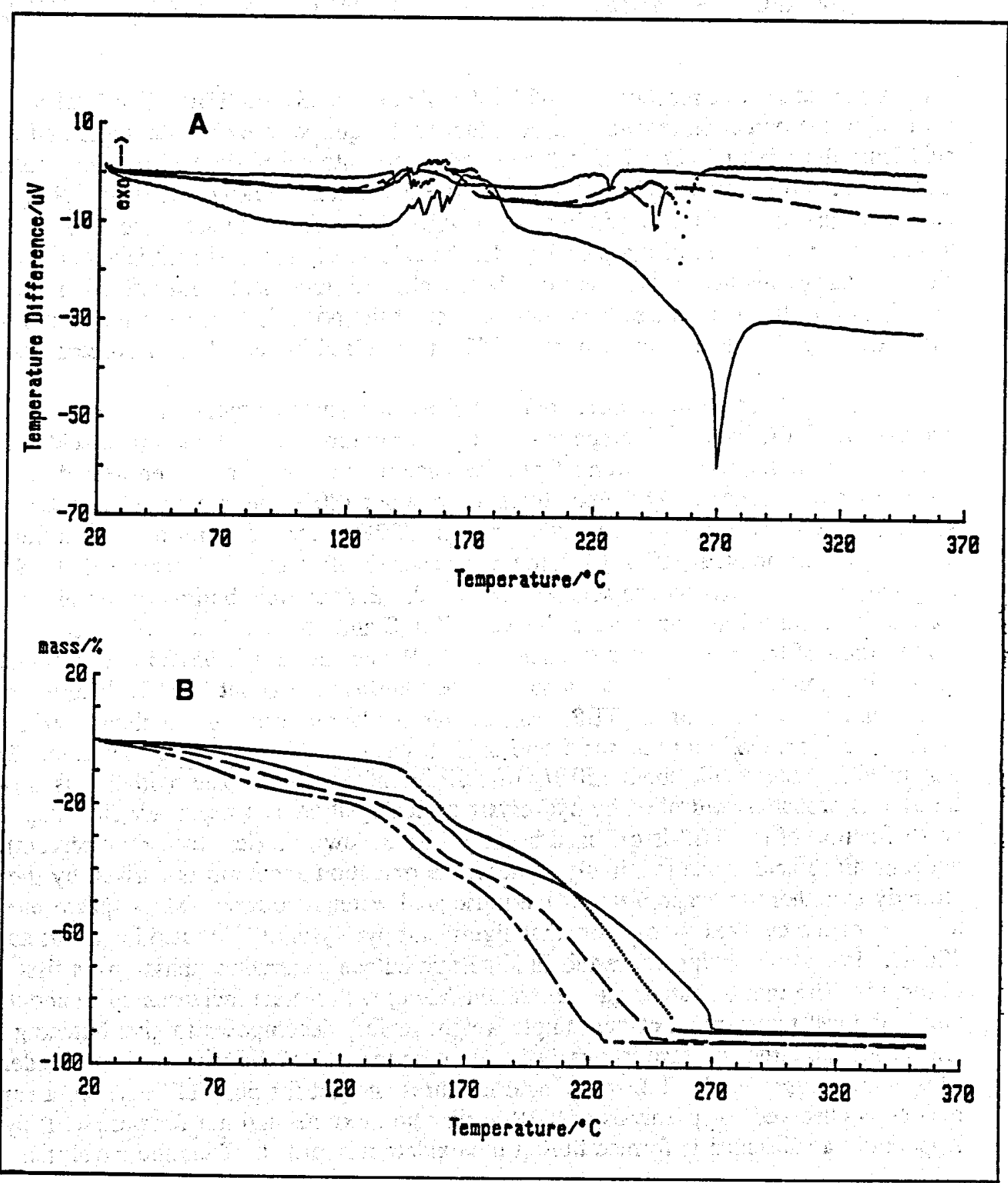


The extent of TBP oxidation in these heated mixtures was estimated by comparing the measured heat evolved to that calculated for complete oxidation of TBP as in the following reaction:

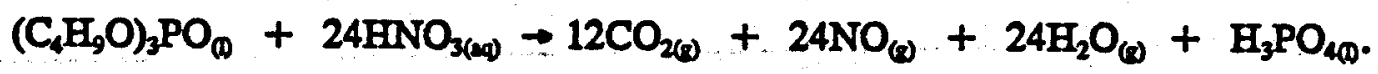

The calculated heat of reaction is $-766 \mathrm{Kcal} /$ mole or $-12,037 \mathrm{~J} / \mathrm{g}$ TBP. The total heat evolved in the oxidation reaction includes that heat required to evaporate water and nitric acid from the mixture. For TBP saturated with concentrated nitric acid (single phase), the TBP contains (by weight) $28 \%$ nitric acid and 3.2\% water (McKay and Healy 1958). Assuming the heats of nitric acid and water vaporization from the saturated TBP are similar to heats of vaporization of the pure liquids, the calculated absorbed heat is about $310 \mathrm{~J} / \mathrm{g}$ of TBP. Adding this heat to the measured heat makes the total heat from oxidation at about $-460 \mathrm{~J} / \mathrm{g}$ of TBP. This is less than four percent of the possible heat from the above reaction and, therefore, less than 4 percent of the TBP is oxidized in heated open process vessels.

The results of all these measurements show that several processes and reactions occur between the $20^{\circ} \mathrm{C}$ to $260^{\circ} \mathrm{C}$ temperature range in mixtures of TBP and nitric acid. Table 5-3 summarizes the sequence of events that take place in these mixtures when heated in a vessel open to the atmosphere. At temperatures up to about $120^{\circ} \mathrm{C}$, no reactions are observed, although a slow hydrolysis or dealkylation of the TBP to form butanol or butyl nitrate and dibutyl phosphoric acid (HDBP) is known to occur (Moffat and Thompson 1960). Some evaporation of the water-nitric acid was observed. Endothermic boiling of the nitric acid solution is observed at temperatures between $120^{\circ} \mathrm{C}$ and $150^{\circ} \mathrm{C}$. This is because the composition of the mixture of nitric acid and TBP changes as it is heated and thus changes the boiling point. Two other reactions become significant at about $120^{\circ} \mathrm{C}$. These are oxidation and pyrolysis of the TBP. Exothermic oxidation occurs up to about $180^{\circ} \mathrm{C}$ at which point essentially all the nitric acid oxidant has evaporated from the solution. The heat generated is quite small, about $150 \mathrm{~J} / \mathrm{g}$ of TBP initially present. The oxidation is slow and the rate is probably controlled by hydrolysis or dealkylation as a necessary first step. Only a small fraction of the TBP is oxidized because of the slow rate (less than four percent). If an aqueous nitric acid phase is initially present, the oxidation exotherm is masked by the strongly endothermic evaporation of the nitric acid-water azeotrope. Mass spectrometric analyses of the evolved gases show that significant pyrolysis of TBP also begins at about $120^{\circ} \mathrm{C}$. It is at this point where the endothermic butene generation (mass 56) is first observed. The rate of butene gas generation (along with water) increases up to about $260^{\circ} \mathrm{C}$ where the last few percent of the sample weight rapidly decomposes to give butene gas. The reason for the large increase in pyrolysis rate near the end of the reaction is not understood. This is only observed for TBP-nitric acid mixtures and not for pure TBP. Also, a carbon residue is observed for pyrolysis of TBP-nitric acid mixtures and not for pure TBP pyrolysis. Apparently a substance is formed during the oxidation step that affects the pyrolysis. 
Table 5-3. Processes Occurring During Heating of TBP-Nitric Acid Mixtures.

\begin{tabular}{|c|c|c|c|}
\hline Temp. Range, ${ }^{\circ} \mathrm{C}$ & Gases Evolved & Heat Flow & Processes Occurring \\
\hline $20-120$ & $\mathrm{H}_{2} \mathrm{O}, \mathrm{HNO}_{3}$ & Endothermic & Evaporation of $\mathrm{H}_{2} \mathrm{O}$ and $\mathrm{HNO}_{3}$ \\
\hline $120-150$ & $\mathrm{H}_{2} \mathrm{O}, \mathrm{HNO}_{3}$ & Endothermic & Boiling of $\mathrm{H}_{2} \mathrm{O}$ and $\mathrm{ENO}_{3}$ \\
\hline $120-180$ & $\mathrm{CO}_{2}, \mathrm{CO}, \mathrm{H}_{2} \mathrm{O}, \mathrm{NO}$, & Exothermic & Oxidation of TBP \\
\hline $120-260$ & $\mathrm{~N}_{2}$ & & \\
\hline $\mathrm{C}_{4} \mathrm{H}_{8}, \mathrm{H}_{2} \mathrm{O}$ & Endothermic & Pyrolysis of TBP \\
\hline
\end{tabular}

The presence of a carbon residue indicates that this substance might be polymeric, but this will require further study to confirm. At $260^{\circ} \mathrm{C}$ pyrophosphoric acid is the major reaction product left in the sample container.

\subsection{TRIBUTYL PHOSPHATE REACTIONS WITH PLUTONIUM NITRATE}

Plutonium nitrate extracted into the TBP phase can also potentially oxidize the TBP. Unlike nitric acid, plutonium nitrate will not evaporate from the mixture at relatively low temperatures, but will remain until the nitrate reacts with the organic phase or until it thermally decomposes. Crystalline plutonium nitrate thermally decomposes over the temperature range of $220^{\circ} \mathrm{C}$ to $250^{\circ} \mathrm{C}$ to form plutonium dioxide and nitrogen oxides. To estimate the reactivity of plutonium nitrate extracted into TBP, thorium(IV) nitrate-saturated TBP was analyzed with the thermoanalyzer-mass spectrometer. The thorium nitrate behaves similarly to plutonium(IV) nitrate in TBP-based solvent extraction systems and also during thermal decomposition. Both compounds form similar complexes with TBP $\left(\mathrm{Pu}\left[\mathrm{NO}_{3}\right]_{4} \cdot 2 \mathrm{TBP}\right.$ and $\left.\mathrm{Th}\left[\mathrm{NO}_{3}\right]_{4}-2 \mathrm{TBP}\right)$. Thermal decomposition of the nitrate compounds occurs over the same temperature range $\left(220^{\circ} \mathrm{C}\right.$ to $\left.270^{\circ} \mathrm{C}\right)$. The general chemical behavior and thermodynamic properties of these two compounds is quite similar. Ahrland (1986) states that "The $\mathrm{Th}^{4+}$ ion is therefore suitable to use as a model for other tetravalent actinide ions . ... Thorium was used as a stand-in for plutonium to prevent radioactive contamination of the instrument.

The results of analysis of $106.5 \mathrm{mg}$ of an organic phase containing TBP $(39.6 \mathrm{mg})$, $\mathrm{Th}\left(\mathrm{NO}_{3}\right)_{4}(41.8 \mathrm{mg}), \mathrm{HNO}_{3}$, and $\mathrm{H}_{2} \mathrm{O}$ (25 mg total) show that no significant exothermic reactions occur in an open system at temperatures from $20^{\circ} \mathrm{C}$ to $360^{\circ} \mathrm{C}$. Figure 5-11 shows a small exotherm at $140^{\circ} \mathrm{C}$ to $180^{\circ} \mathrm{C}$ due to nitric acid reaction with TBP. This exotherm is partially hidden by the endothermic evaporation of nitric acid and water dissolved in the TBP (note the weight loss). Some pyrolysis of the TBP also occurs in this temperature range as indicated by the release of butene according to the mass spectrometric data. TBP pyrolysis continues up to $300^{\circ} \mathrm{C}$ where all the reactions stop. Calcination of the thorium nitrate occurs between about $180^{\circ} \mathrm{C}$ and $250^{\circ} \mathrm{C}$. At $300^{\circ} \mathrm{C}$ the final remaining decomposition products are probably a mixture of $\mathrm{ThP}_{2} \mathrm{O}_{7}$ and $\mathrm{H}_{4} \mathrm{P}_{2} \mathrm{O}_{7}$. The small exotherms in the temperature range of 
Figure 5-11. TG (..) and DTA (-) Curves for TBP Saturated with Thorium Nitrate and Concentrated Nitric Acid (39.6 mg TBP, $41.8 \mathrm{mg} \mathrm{Th}\left(\mathrm{NO}_{3}\right)_{4}$, and $25.0 \mathrm{mg} \mathrm{HNO}+\mathrm{HN}_{2} \mathrm{O}$ ). Atmosphere $=$ Argon, Flow Rate $=100 \mathrm{cc} / \mathrm{min}$, Heating Rate $=3.0 \mathrm{C} / \mathrm{min}$.

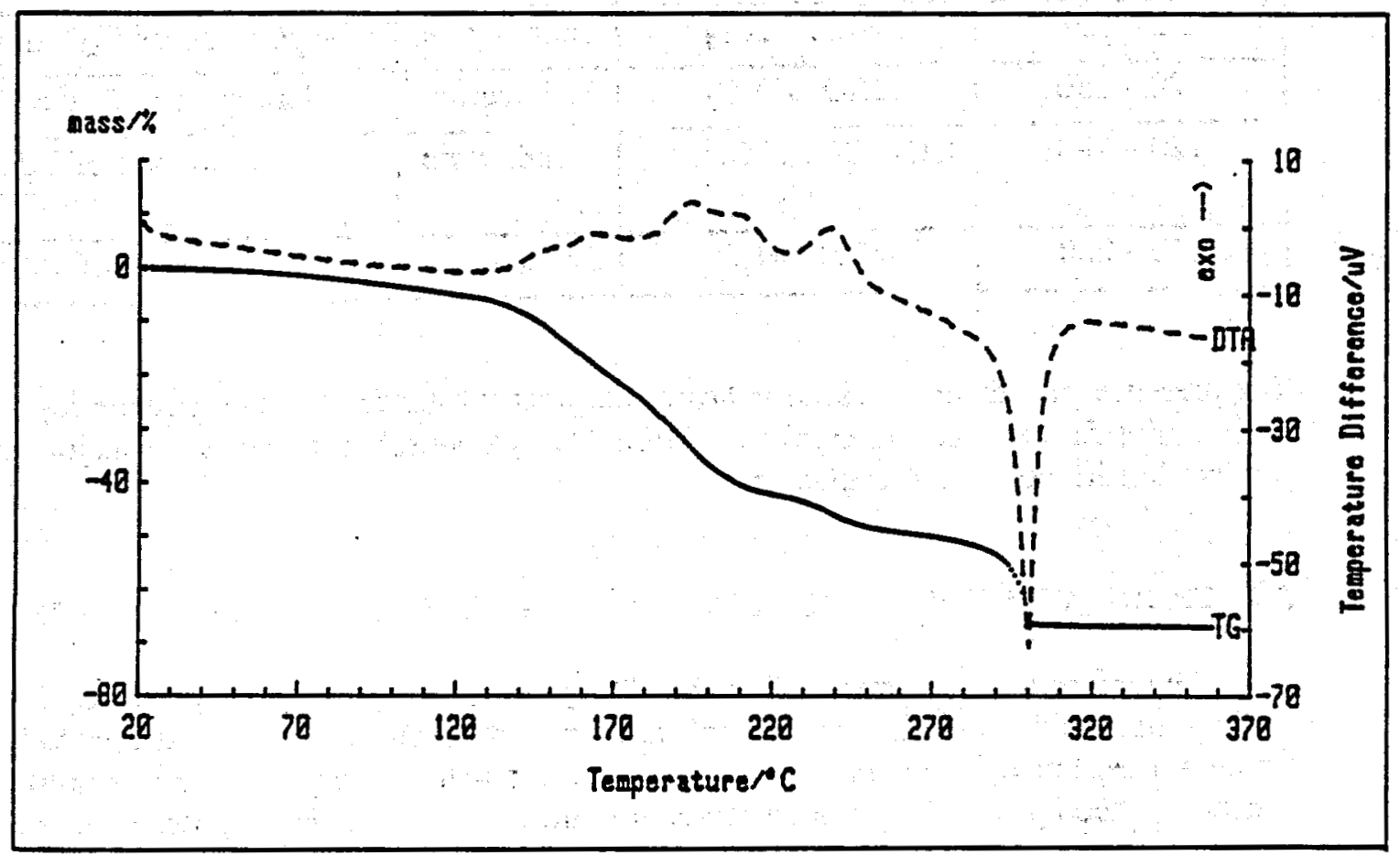

$180^{\circ} \mathrm{C}$ to $250^{\circ} \mathrm{C}$ correspond to about 218 Joules/g of TBP initially present. The reactions of thorium nitrate and thermal decomposition products of thorium nitrate $\mathrm{NO}_{x}$ gases) with TBP are quite slow and do not generate great amounts of heat before the oxidant is evolved from the mixture and the reaction stops. The heat generated by thorium reaction is greater than the heat generated for reaction of TBP with nitric acid.

Several workers have reported butyl nitrate to be a major reaction product of TBP-uranyl nitrate reactions (Moffat and Thompson 1960; Harmon et al. 1976; Pushlenkov and Usachev 1968). The mass spectra of gases evolved at $161^{\circ} \mathrm{C}, 245^{\circ} \mathrm{C}$, and $302^{\circ} \mathrm{C}$ from the run with thorium nitrate were examined for the presence of butyl nitrate. These spectra and the spectra of pure butyl nitrate and pure butene are shown in Figures 5-12, 5-13, and 5-14. Comparison of the known spectra with those of the evolved gases prove that butyl nitrate is not a major reaction product. The characteristic peaks for butyl nitrate at mass 46 $\left(\mathrm{NO}_{2}{ }^{+}\right)$, mass $76\left(\mathrm{CH}_{2} \mathrm{ONO}_{2}{ }^{+}\right)$, and mass 59 (CHONO${ }^{+}$) are all missing from the evolved gas spectra. The spectrum obtained at $302^{\circ} \mathrm{C}$ is essentially the same as that of pure 1-butene. The lower temperature spectra show the presence of butene, $\mathrm{CO}_{2}$ (mass 44) and a small amount of gas(es) producing ion fragments of mass $72\left(\mathrm{C}_{4} \mathrm{H}_{8} \mathrm{O}^{+}\right.$?) and mass 70 $\left(\mathrm{C}_{4} \mathrm{H}_{6} \mathrm{O}^{+}\right.$?) 
Figure 5-12. Mass Spectra of TBP Saturated with Thorium Nitrate and Concentrated Nitric Acid Heated to $161^{\circ} \mathrm{C}(\mathrm{A})$ and $245^{\circ} \mathrm{C}(\mathrm{B})$.

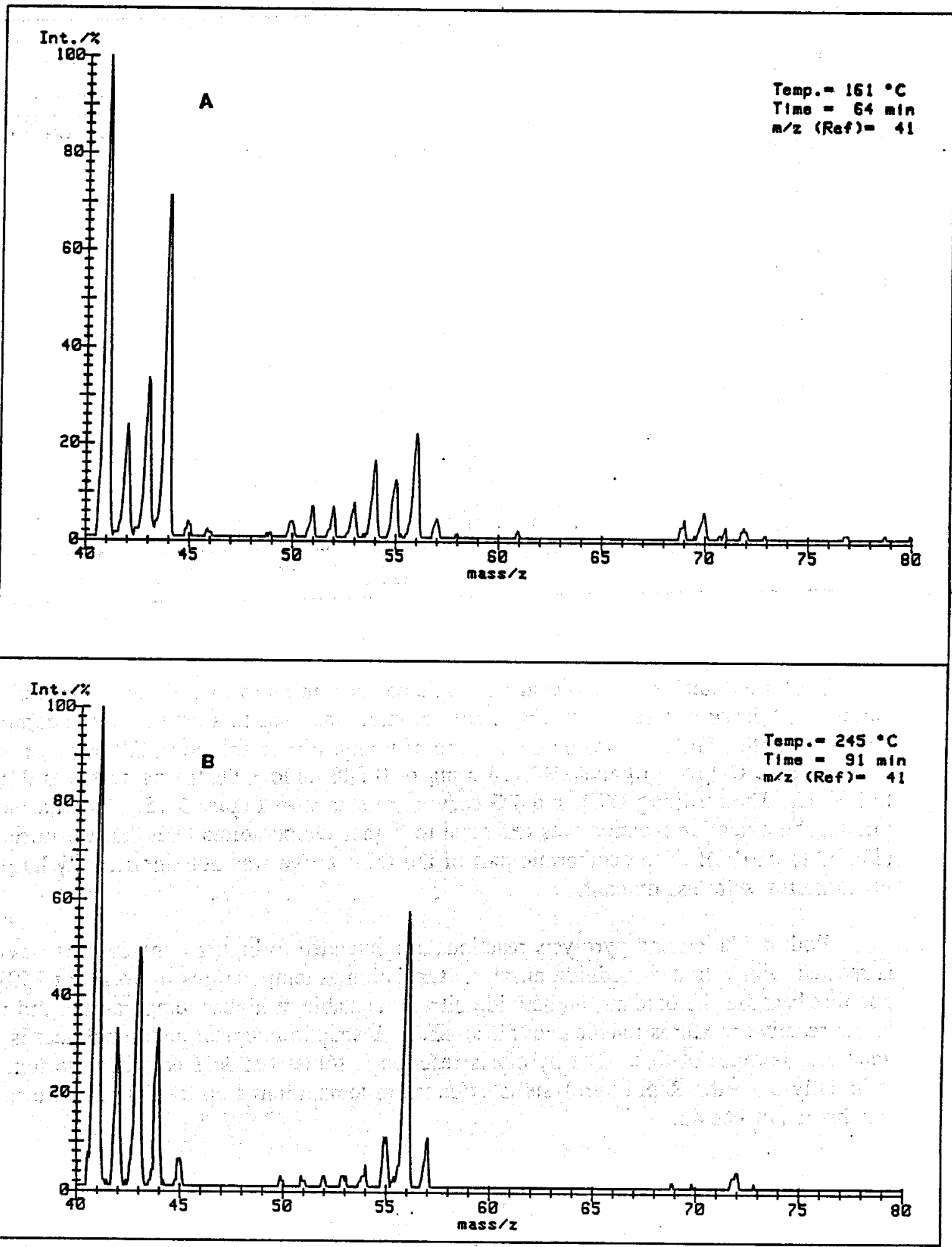


Figure 5-13. Mass Spectrum of TBP Saturated with Thorium Nitrate and Concentrated Nitric Acid Heated to $302^{\circ} \mathrm{C}$.

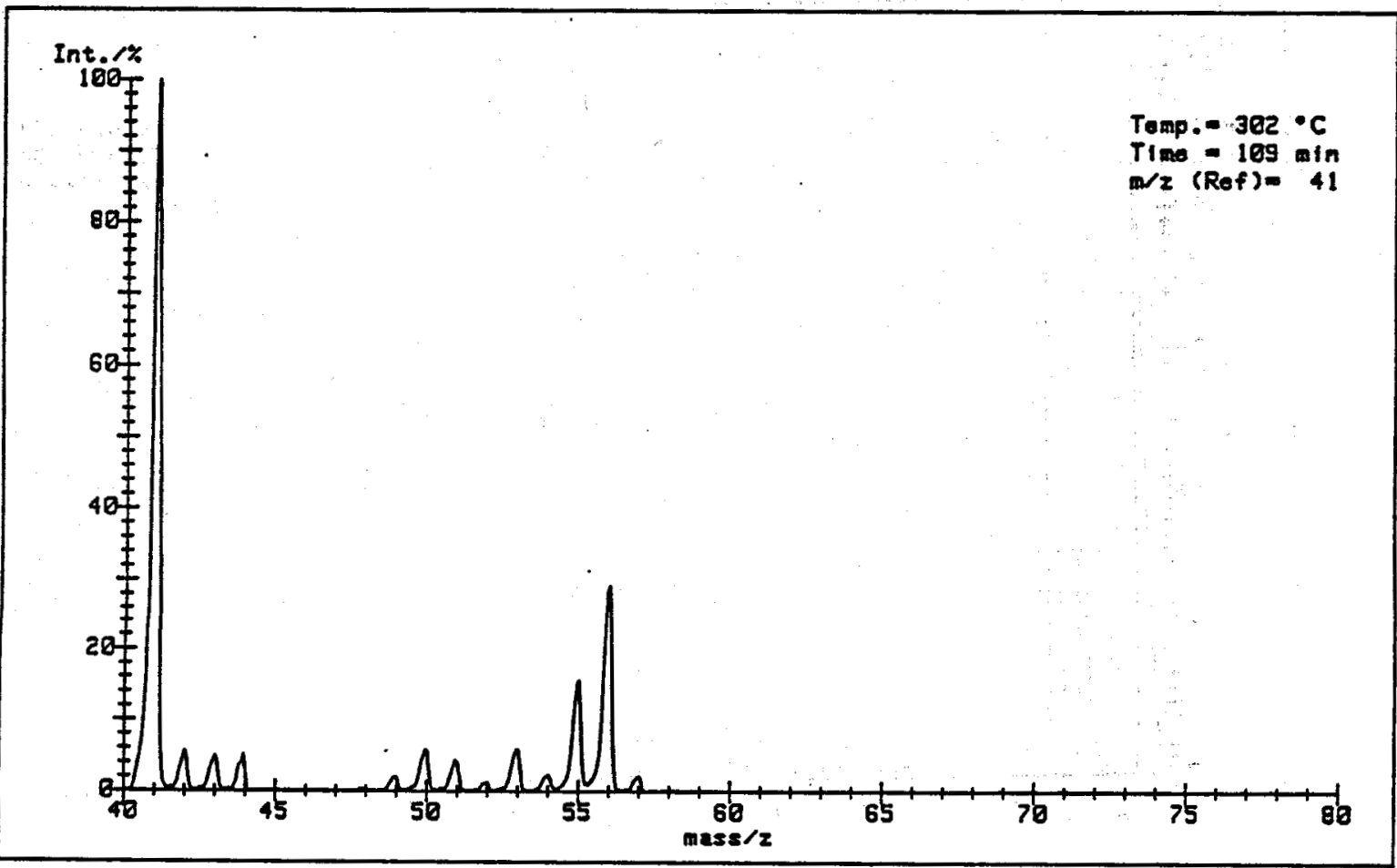

A thermal analysis run was also completed for a mixture of TBP and uranyl nitrate solution. A large excess of oxidant, uranyl nitrate, was used to attempt a more complete oxidation of the TBP. A two-phase mixture of uranyl nitrate solution [229.5 mg or 0.093 mmole $\mathrm{UO}_{2}\left(\mathrm{NO}_{3}\right)_{2}$ ] and TBP $\left(28.3 \mathrm{mg}\right.$ or $0.088 \mathrm{mmole}$ TBP) was heated at $3^{\circ} \mathrm{C} / \mathrm{min}$ to $360^{\circ} \mathrm{C}$. The resulting DTA and TG curves are shown in Figure 5-15. As with thorium nitrate, the oxidation reaction was extended to higher temperatures than that for nitric acid $\left(170^{\circ} \mathrm{C}\right.$ to $\left.210^{\circ} \mathrm{C}\right)$. The exothermic part of the DTA curve was not significantly larger than for mixtures with less oxidant.

Both oxidation and pyrolysis reactions are extended to higher temperatures when TBP is reacted with extracted actinide nitrates. Oxidation at temperatures up to about $250^{\circ} \mathrm{C}$ is possible because the oxidant, an actinide nitrate, is stable at higher temperatures and remains in the reactive mixtures longer than nitric acid. A small amount of additional heat is generated because of this. The pyrolysis reaction is somewhat delayed when thorium nitrate is initially present. Rapid pyrolysis is extended at temperatures up to $300^{\circ} \mathrm{C}$. The reason for this is not known. 
Figure 5-14. Mass Spectra of Pure 1-Butyl Nitrate Standard Heated to $129^{\circ} \mathrm{C}$ (A) and Pure 1-Butene Standard (B).

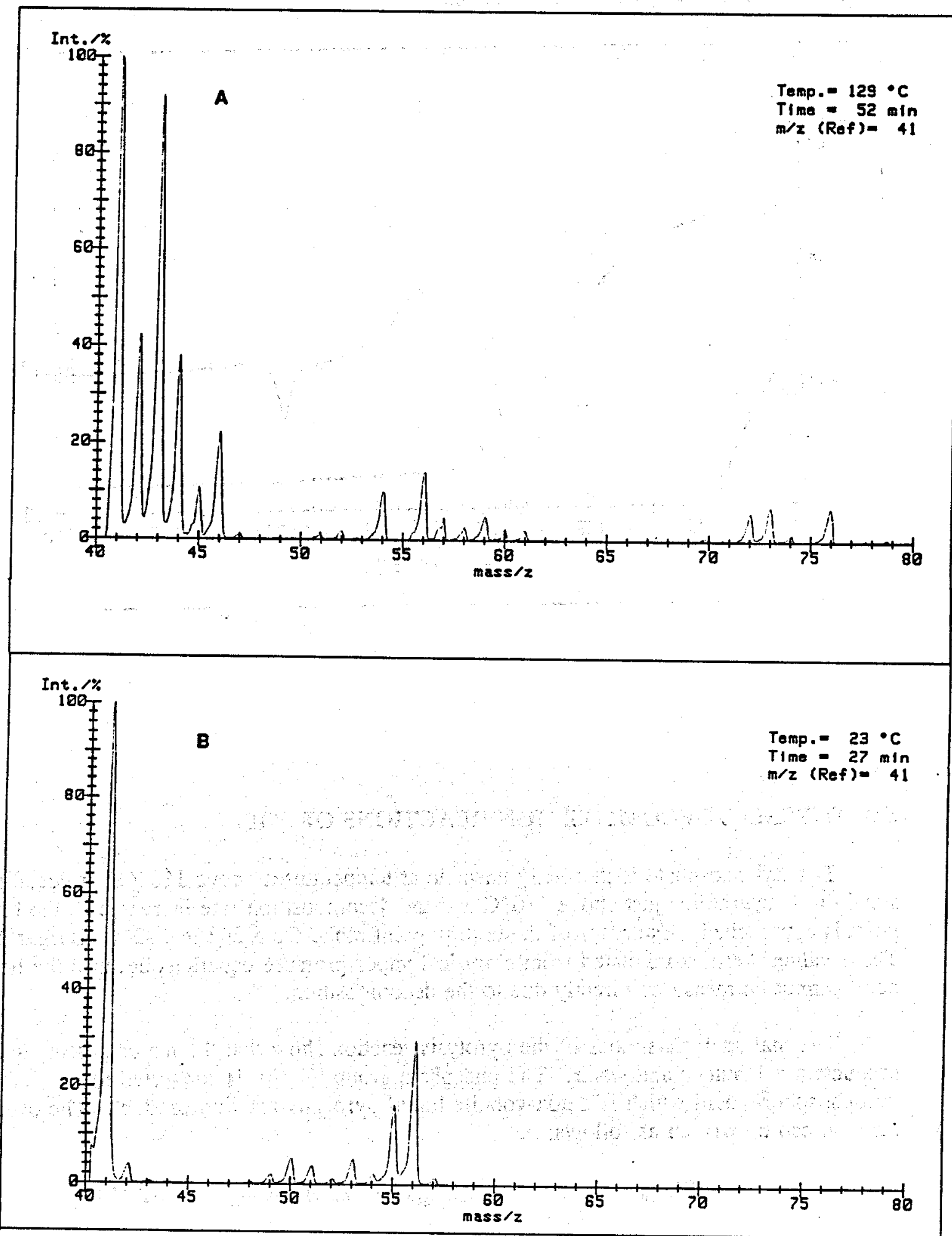


Figure 5-15. TG (..) and DTA $($ ) Curves for a Mixture of TBP (28.3 mg) and Uranyl Nitrate Solution (229.5 mg of a $111 \mathrm{mg} \mathrm{U} / \mathrm{mL}$ solution). Atmosphere = Argon, Flow Rate $=100 \mathrm{cc} / \mathrm{min}$, Heating Rate $=3.0^{\circ} \mathrm{C} / \mathrm{min}$.

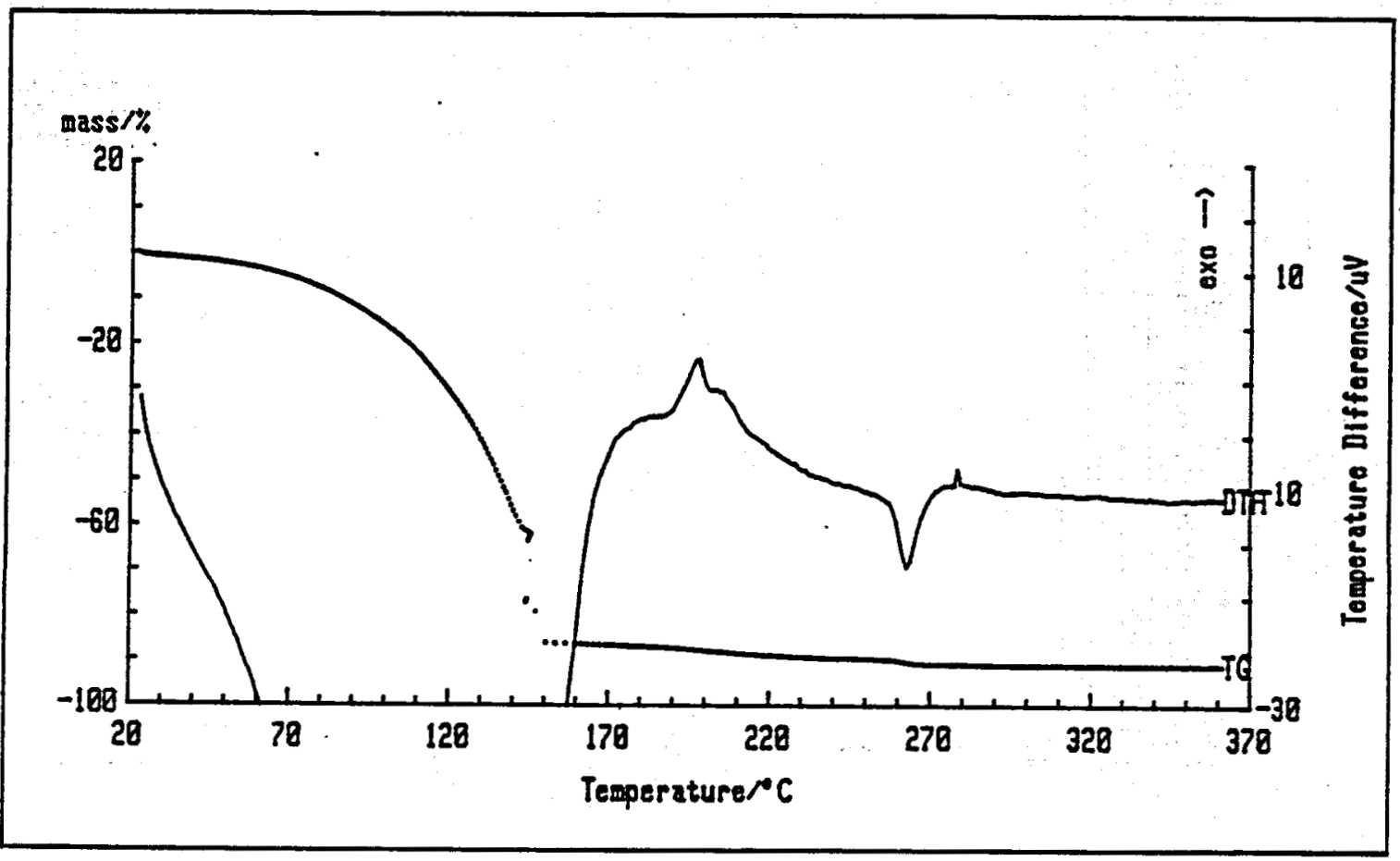

\subsection{THERMAL DECOMIPOSITION REACTIONS OF TBP}

Tributyl phosphate is thermally unstable at temperatures above $110^{\circ} \mathrm{C}$. It decomposes slowly at temperatures just above $110^{\circ} \mathrm{C}$ and the decomposition rate increases as the boiling point is approached. Estimates of the boiling point range from 268 to $293^{\circ} \mathrm{C}$ (Burger 1984). These values were extrapolated from empirical vapor pressure equations because the boiling point cannot be measured directly due to the decomposition.

Thermal analysis studies of the pyrolysis reaction show that the major gaseous reaction products are 1-butene and water. The phosphate group in TBP is converted to pyrophosphoric acid which is a non-volatile liquid pyrolysis reaction product. The overall reaction can be written as follows:

$$
\left(\mathrm{C}_{4} \mathrm{H}_{9} \mathrm{O}\right)_{3} \mathrm{PO}_{(\mathrm{iq})}+\text { heat }=3 \mathrm{C}_{4} \mathrm{H}_{8(\mathrm{gus})}+1 / 2 \mathrm{H}_{4} \mathrm{P}_{2} \mathrm{O}_{7(\mathrm{liq})}+1 / 2 \mathrm{H}_{2} \mathrm{O}_{(\mathrm{gur})} \text {. }
$$


Higgins and Baldwin (1965) have shown that some 2-butene is also formed at temperatures of $241^{\circ} \mathrm{C}$ to $245^{\circ} \mathrm{C}$ in the latter stages of the pyrolysis of pure TBP.

Figure 5-16 compares DTA and TG curves for pure TBP and TBP saturated with concentrated nitric acid. TBP extracts about $35 \%$ by weight nitric acid at equilibrium. The pyrolysis of TBP is somewhat affected by prior oxidation reactions with nitric acid. The shapes of the DTA and TG curves during pyrolysis are changed by the oxidation. 1-Butene gas is the major gaseous reaction product from heating pure TBP, mixtures of TBP and nitric acid solutions, or TBP and uranyl nitrate solutions. Thermal analysis studies of reactions of nitric acid with TBP show that butene is produced at approximately the same rate from these mixtures as from pure TBP. Figure 5-17 compares the mass intensity curves for mass 56 (the butene parent peak) versus temperature for pure TBP and TBP saturated with concentrated nitric acid. For pure TBP, butene evolution begins at $110^{\circ} \mathrm{C}$. Butene is first detected at $120^{\circ} \mathrm{C}$ for the nitric acid-saturated TBP phase. The rate of butene generation increases over several orders of magnitude from $122^{\circ} \mathrm{C}$ to $260^{\circ} \mathrm{C}$ for both samples. The rates of butene gas generation are similar. The rates of butene gas generation per gram of TBP per minute for pure TBP at various temperatures are shown in Table 5-4. The rates were calculated from sample weight loss measurements and identification of butene and water vapor as the gaseous reaction products.

Table 5-4. Rates of Butene Gas Generation from TBP Pyrolysis.

\begin{tabular}{|c|c|}
\hline Temperature, $^{\circ} \mathrm{C}$ & Butene Generation Rate, $\mathrm{g} / \mathrm{min} / \mathrm{g}$ TBP \\
\hline 112 & 0.00024 \\
\hline 132 & 0.0014 \\
\hline 152 & 0.0033 \\
\hline 172 & 0.0084 \\
\hline 192 & 0.022 \\
\hline 212 & 0.045 \\
\hline 232 & 0.11 \\
\hline 252 & 0.33 \\
\hline 268 & 3.43 \\
\hline
\end{tabular}

These rates are similar to rates of butene gas generation in TBP-nitric acid mixtures. An Arrhenius plot of the rates is shown in Figure 5-18. The last two high temperature values shown in the plot were not included in the regression line because a different mechanism for the pyrolysis appears to be occurring at these temperatures. The calculated activation energy is $18.9 \mathrm{kcal} / \mathrm{mole}(79.1 \mathrm{~kJ} / \mathrm{mole})$. The heat of pyrolysis was measured to be $228 \mathrm{~J} / \mathrm{g}$ of TBP over this temperature range. 
Figure 5-16. Comparison of TG (A) and DTA (B) Curves for Pure TBP (..) and TBP Saturated with Concentrated Nitric Acid $(J .100 .1 \mathrm{mg}$ of Pure TBP and $80.4 \mathrm{mg}$ TBP + $29.7 \mathrm{mg} \mathrm{HNO}$. Atmosphere $=$ Argon, Flow Rate $=100 \mathrm{cc} / \mathrm{min}$, Heating Rate $=3.0$ - C/min.

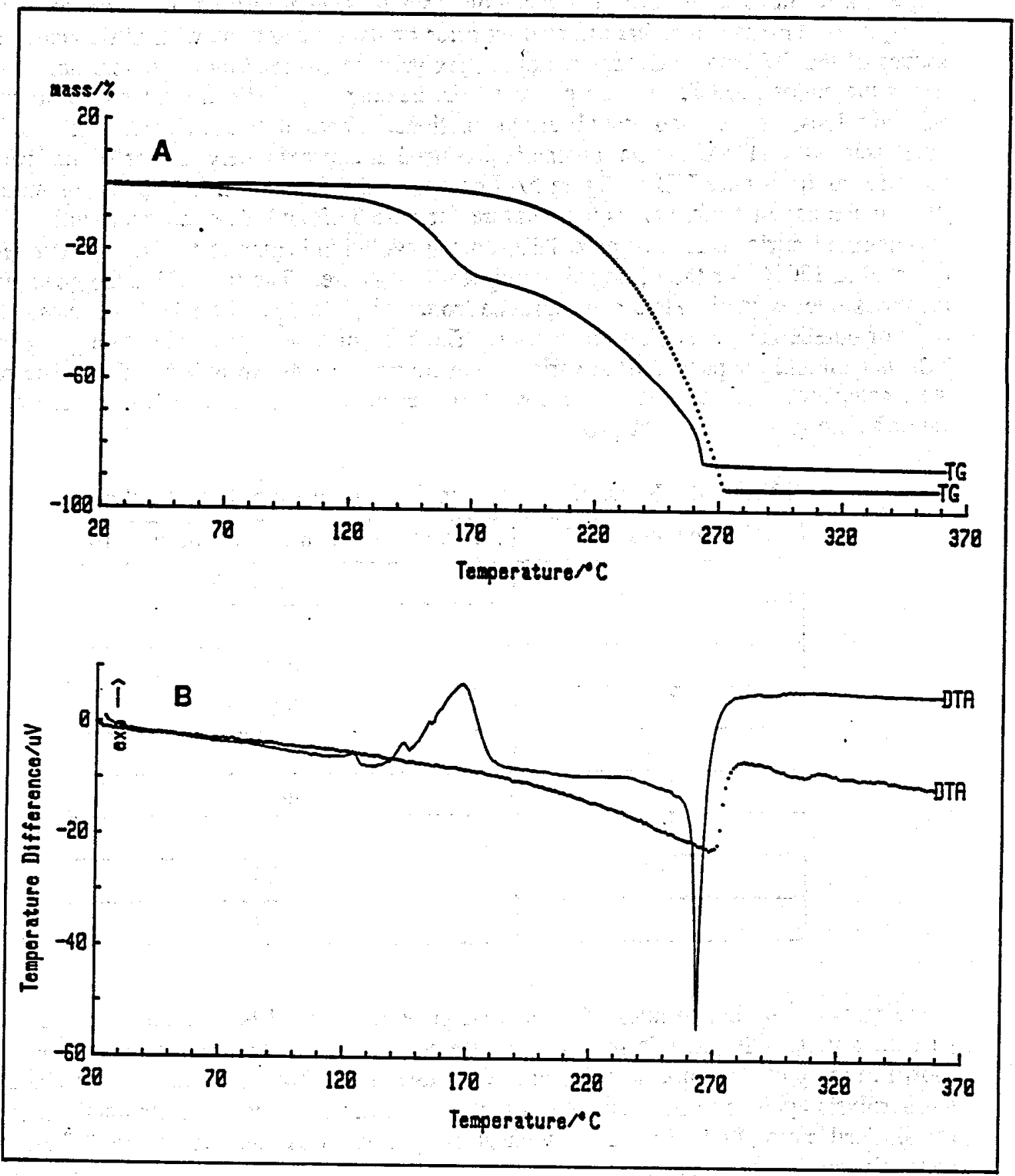


Figure 5-17. Comparison of Mass 56 Intensities for Pure TBP (**) and TBP Saturated with Concentrated Nitric Acid ( $)$ over a $20^{\circ} \mathrm{C}$ to $360^{\circ} \mathrm{C}$ Temperature Range. $100.1 \mathrm{mg}$ of Pure TBP and $80.4 \mathrm{mg}$ TBP $+29.7 \mathrm{mg} \mathrm{HNO}$. Atmosphere = Argon, Flow Rate $=100 \mathrm{cc} / \mathrm{min}$, Heating Rate $=3.0^{\circ} \mathrm{C} / \mathrm{min}$.

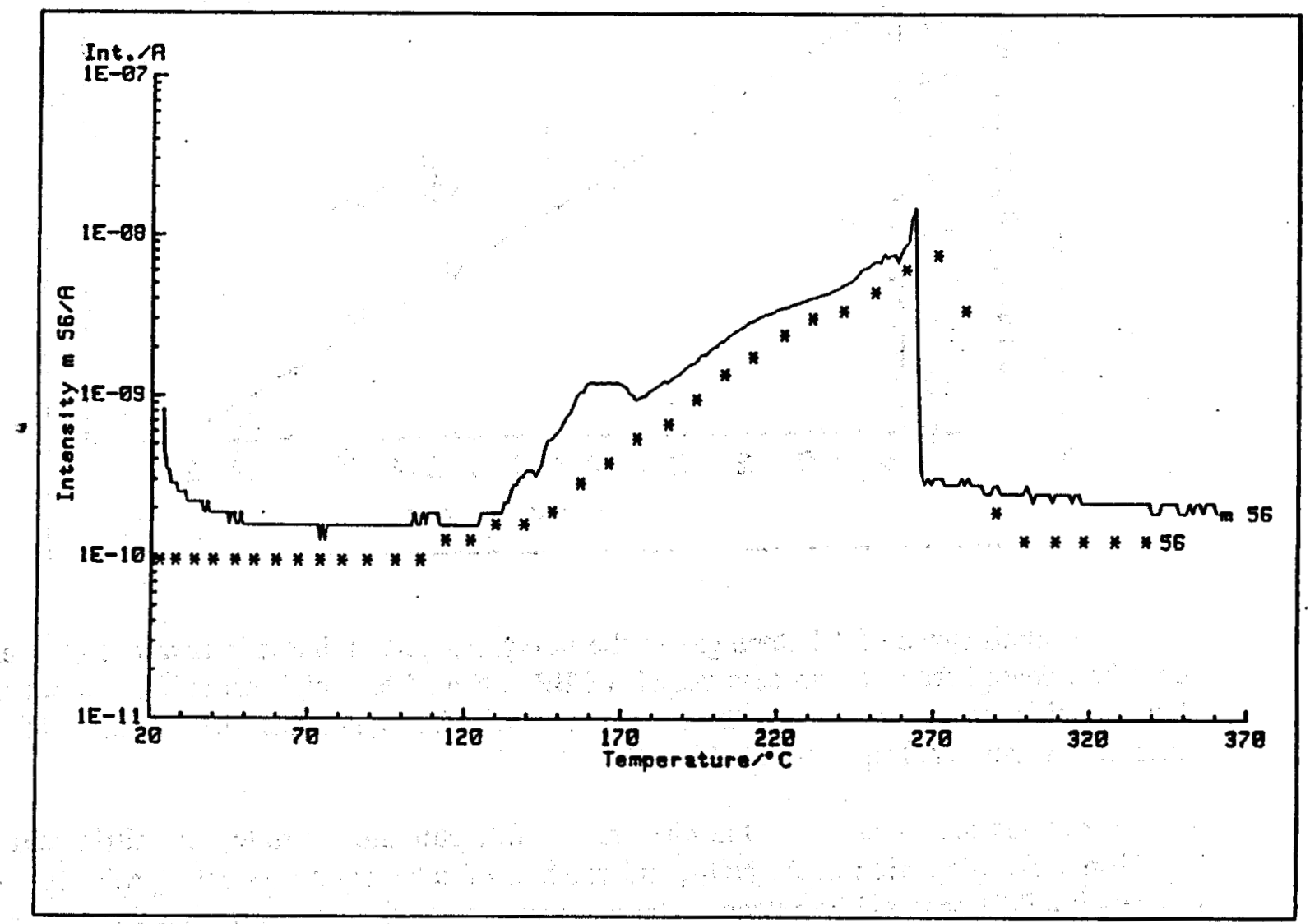


WHC-EP-0737

Figure 5-18. Arrhenius Plot of Butene Generation Rates Versus Temperature.

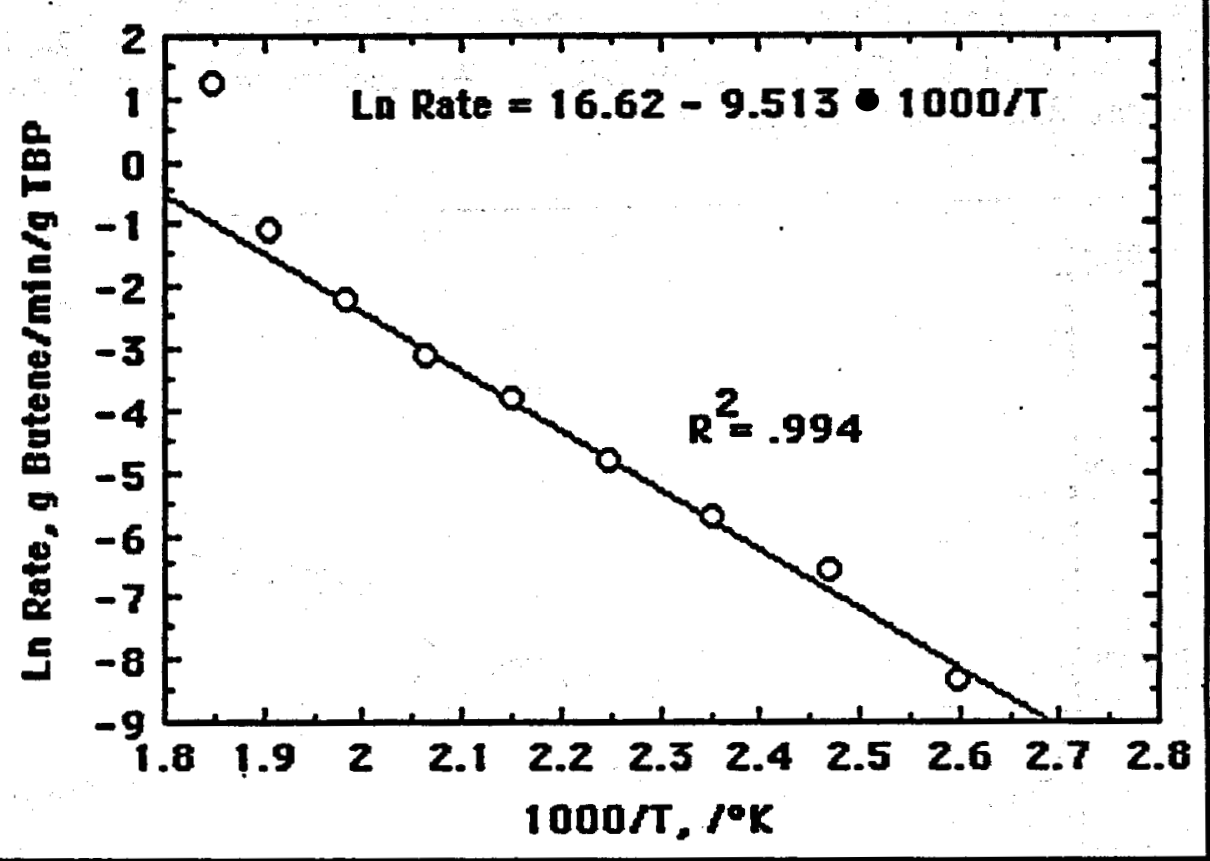

The significance of 1-butene gas in the safety analysis is that it is flammable in air and could be released from the process vessel if TBP is heated to a high enough temperature. To obtain significant butene releases the temperature must be higher than the boiling point of the nitric acid-water azeotrope (about $122^{\circ} \mathrm{C}$ ).

Reactions that occur when the mixture of TBP, plutonium nitrate, and nitric acid is heated include calcination of $\mathrm{Pu}\left(\mathrm{NO}_{3}\right)_{4}$ and reaction of calcination products (probably $\mathrm{NO}_{2}$ gases) with TBP or possibly butene. The mass spectrometric data show that the exothermic peaks observed from $180^{\circ} \mathrm{C}$ to $250^{\circ} \mathrm{C}$ coincide with high generation rates of butene. This observation indicates that butene is probably being oxidized by $\mathrm{NO}_{\mathrm{x}}$ gases (the nitric acid is gone at these temperatures). The calcination reaction can be written as follows:

$$
\mathrm{Pu}\left(\mathrm{NO}_{3}\right)_{4} \cdot 2 \mathrm{TBP} \rightarrow \mathrm{PuO}_{2}+2 \mathrm{TBP}+2 \mathrm{NO}+2 \mathrm{NO}_{2}+2 \mathrm{O}_{2}
$$

The reactions involving oxidation of the butene with $\mathrm{NO}_{x}$ gases are not well understood. 


\subsection{CONCLUSIONS}

The major reactions between TBP and nitric acid in an open, heated system are 1) a slow, exothermic oxidation of TBP by nitric acid and 2) a slow, endothermic pyrolysis reaction of TBP. At high nitric acid concentrations, the initial rate controlling step in the oxidation reaction probably occurs by one or both of the following reactions:

$$
\begin{aligned}
& \left(\mathrm{C}_{4} \mathrm{H}_{9} \mathrm{O}\right)_{3} \mathrm{PO}+\mathrm{H}_{2} \mathrm{O} \rightarrow\left(\mathrm{C}_{4} \mathrm{H}_{9} \mathrm{O}_{2} \mathrm{POOH}+\mathrm{C}_{4} \mathrm{H}_{9} \mathrm{OH}\right. \text { (Slow Hydrolysis) } \\
& \left(\mathrm{C}_{4} \mathrm{H}_{9} \mathrm{O}\right)_{3} \mathrm{PO}+\mathrm{HNO}_{3} \rightarrow\left(\mathrm{C}_{4} \mathrm{H}_{9} \mathrm{O}_{2} \mathrm{POOH}+\mathrm{C}_{4} \mathrm{H}_{9} \mathrm{ONO}_{2}\right. \text { (Slow Nitration) }
\end{aligned}
$$

If butanol is produced, it will be rapidly converted to butyl nitrate by the following reaction:

$$
\mathrm{C}_{4} \mathrm{H}_{9} \mathrm{OH}+\mathrm{HNO}_{3} \rightarrow \mathrm{C}_{4} \mathrm{H}_{9} \mathrm{ONO}_{2}+\mathrm{H}_{2} \mathrm{O} \text {. }
$$

Butyl nitrate will then rapidly decompose to form carbon dioxide, nitric oxide, and water. This involves a number of reaction steps with reactive free radicals. The overall reaction will be:

$$
\mathrm{C}_{4} \mathrm{H}_{9} \mathrm{ONO}_{2}+7 \mathrm{HNO}_{3} \rightarrow 4 \mathrm{CO}_{2}+8 \mathrm{NO}+8 \mathrm{H}_{2} \mathrm{O} \text { (Rapid Oxidation). }
$$

Neither butyl nitrate nor butanol was observed in the mass spectral data for the temperature range studied $\left(20^{\circ} \mathrm{C}\right.$ to $\left.360^{\circ} \mathrm{C}\right)$. The hydrolysis or nitration reactions are rate-limiting so that the overall oxidation reaction rate is the same as the hydrolysis or nitration rate. In an open (vented) system, the extent of the TBP oxidation is small. Less than four percent of the TBP initially present is oxidized, even when a large excess of nitric acid is present. This is due to escape of the nitric acid by vaporization at higher temperatures. Comparison of measured rate constants for the hydrolysis or nitration reactions and oxidation reactions of TBP show that they are nearly the same. The measured exothermic heat released from the oxidation reaction was about $-150 \mathrm{~J} / \mathrm{g}$ TBP for a two-phase mixture of TBP and concentrated nitric acid, and $-120 \mathrm{~J} / \mathrm{g}$ TBP for single-phase TBP saturated with concentrated nitric acid. The oxidation is more extensive when more nitric acid is initially present, but this exothermic reaction is hidden by endothermic vaporization of nitric acid and water.

The pyrolysis reaction occurs as follows:

$$
2\left(\mathrm{C}_{4} \mathrm{H}_{9} \mathrm{O}\right)_{3} \mathrm{PO} \rightarrow 6 \mathrm{C}_{4} \mathrm{H}_{8}+\mathrm{H}_{2} \mathrm{O}+\mathrm{H}_{4} \mathrm{P}_{2} \mathrm{O}_{7} \text { (Slow Pyrolysis). }
$$

The pyrolysis rate of pure TBP was measured over the temperature range of $112^{\circ} \mathrm{C}$ to $268^{\circ} \mathrm{C}$ with the thermoanalyzer-mass spectrometer under argon cover gas. Water and 1-Butene were the only pyrolysis products found in the evolved gases. The heat of pyrolysis was measured to be $228 \mathrm{~J} / \mathrm{g}$ of TBP for this temperature range. The rate of pyrolysis increased rapidly at higher temperatures. At $252^{\circ} \mathrm{C}$ the rate was $0.33 \mathrm{~g}$ butene produced $/ \mathrm{g}$ of TBP present. The activation energy for this reaction was $18.9 \mathrm{kcal} / \mathrm{mole}(79.4 \mathrm{~kJ} / \mathrm{mole})$. 
Reactions of TBP with plutonium nitrate in an open system are expected to be relatively slow at expected temperatures in heated process vessels in the PFP. This conclusion is based on results of thermal analyses of TBP mixtures with thorium and uranium nitrates used as stand-ins for plutonium nitrate. Thermal analyses of thorium nitrate and uranium nitrate extracted into TBP show that oxidation is extended to higher temperatures (up to about $250^{\circ} \mathrm{C}$ ). The reaction is still relatively slow at these temperatures since only a few percent of the initial TBP was oxidized by the actinide nitrates. The heat produced by the oxidation reaction with thorium nitrate was $218 \mathrm{~J} / \mathrm{g}$ of TBP, which is somewhat higher than for oxidation with nitric acid. The reaction products observed were similar to those observed from the nitric acid reaction: carbon dioxide, nitric oxide, nitrogen, and water from the oxidation reaction and 1-butene and water from the pyrolysis reaction of TBP. Again, no butyl nitrate or butanol were observed in the evolved gases at any temperature.

The results of these studies provide information that is essential for the safety analyses of the heated process vessels at the PFP. In summary, it was found that:

(1) No violent reactions will occur between TBP and nitric acid or plutonium nitrate in the vented, heated process vessels. Exothermic oxidation reactions will begin if the temperature of the vessel is about $125^{\circ} \mathrm{C}$, but the reactions are slow. These reactions may raise the temperature, but a simultaneous endothermic reaction (pyrolysis) will cool the vessel. The exothermic reaction will stop when the nitrate oxidant is removed from the vessel by vaporization or decomposition. Only a few percent of the TBP will be oxidized before the oxidant is gone.

(2) Additional endothermic processes occur that reduce the overall heat evolved from the mixtures. These are a) evaporation of nitric acid and water at temperatures ranging from about $122^{\circ} \mathrm{C}$ to $185^{\circ} \mathrm{C}$, and b) calcination of plutonium nitrate to form $\mathrm{NO}_{x}$ gases and $\mathrm{PuO}_{2}$.

(3) Generation of flammable butene gas may be significant for the safety analyses but only if the temperature rise due to the oxidation reaction is significant. Butene generation rates at normal operating temperatures in the process vessels are small. 


\subsection{FUTURE WORK}

Future study of chemical reactions of TBP will attempt to clarify the oxidation reaction between TBP and nitric acid or plutonium nitrate. The rate-controlling step can either be hydrolysis or dealkylation reactions of TBP (or possibly both). The hydrolysis reaction will be studied using non-oxidizing acids to identify the chemical processes. In addition, the oxidation of butanol and butyl nitrate will be examined at lower temperatures to identify reactions and reaction rates. Non-volatile reaction products will also be identified. 
WHC-EP-0737

This page intentionally left blank. 


\subsection{REFERENCES}

Ahrland, S., 1986, "Solution Chemistry and Kinetics of Ionic Reactions," The Chemistry of the Actinide Elements, Vol. 2, J. J. Katz, G. T. Seaborg, and L. R. Morss, Eds., Chapman and Hall, New York, New York.

Burger, L. L., 1984, "Physical Properties," Science and Technology of Tributyl Phosphate, Vol. 1, W. W. Schulz and J. D. Navratil, Eds., CRC Press, Inc., Boca Raton, Florida, p. 28.

Campbell, D. O. and J. C. Mailen, 1988, The Red Oil Problem and its Impact on Purex Safety, ORNL/TM-10798, Martin Marietta, Oak Ridge National Laboratory, Oak Ridge, Tennessee.

Colvin, Jr., T. J., G. M. Nichols, and T. H. Siddall, 1953, Interim Technical Report - TNX Evaporator Incident January 12, 1953, DP-25, E. I. du Pont de Nemours \& Co., Savannah River Laboratory, Augusta, Georgia.

DOE, 1993, Trip Report - Moscow and Tomsk, Russia, June 19-29, 1993, Follow-Up to the Tomsk-7 Accident, DOE/DP-0120, U. S. Department of Energy, Washington, D.C.

Durant, W. S., 1983, Red Oil Explosions at the Savannah River Plant, DP-MS-83-142, E. I. du Pont de Nemours \& Co., Savannah River Laboratory, Augusta, Georgia.

Harmon, H. D., M. L. Hyder, B. Tiffany, L. W. Gray, and P. A. Soltys, 1976, Behavior of Tributyl Phosphate in A-Line Processes, DP-1418, E. I. du Pont de Nemours \& Co., Savannah River Laboratory, Augusta, Georgia.

Higgins, C. E. and W. H. Baldwin, 1965, "The Pyrolysis of n-Butyl Phosphate Esters and Salts," J. Org. Chem., 3173-76.

Li, Shaobai^Zhang, Shaoming^Wu, Kai^Li, Yulin, 1992, "Preparation of Carboxylic Acids by Oxidation of Primary Alcohols with Boiling Concentrated Nitric Acid," Huaxue Shiji, 14, 60 .

McKay, H. A. C. and T. U. Healy, 1958, "Tri-n-Butyl Orthophosphate as an Extraction Solvent," Progress in Nuclear Energy Process Chemistry, Vol. 2, F. R. Bruce, J. M. Fletcher, and J. J. Hyman, Eds., pp. 546-564.

Moffat, A. J., and R. D Thompson, 1960, "The Chemical Stability of Tributyl Phosphate in Some Nitrate and Chloride Systems," Joumal of Inorganic \& Nuclear Chemistry, Vol. 16, 365-366. 
Nichols, G. S., 1960, Decomposition of the Tributyl Phosphate-Nitrate Complexes, DP-526, E. I. du Pont de Nemours \& Co., Savannah River Laboratory, Augusta, Georgia.

Perkins W. C., W. S. Durant, M. L. Hyder, 1977, The Safety of UO, Production in the A-Line at the Sovarmah River Plant, DP-1449, E. I. du Pont de Nemours \& Co., Savannah River Laboratory, Augusta, Georgia.

Pugh, R. A., 1954, Notes Pertaining to RECUPLEX Product Evaporation, HW-32100, General Electric Company, Richland, Washington.

Pushlenkov, M. F. and V. N. Usachev, 1968, "On the Thermal Stability of the Dissolvate $\mathrm{UO}_{2}\left(\mathrm{NO}_{3}\right) \cdot 2 \mathrm{TBP}, "$ Radiokhimiya, Vol. 10.

Sege, G., 1953, Overconcentration in Initial Operation of Uranium Evaporator - 321 Building, HW-28690, General Electric Company, Richland, Washington.

Steiglitz, L., R. Becker, H. Bautz, R. Will, 1986 "Properties of Heavy Organic Phases and their Formation in the PUREX Process," Proceedings of International Solvent Extraction Conference, ISEC '86, 11-16 September, 1986, Munchen, FRG.

Wagner R.M., 1952, Nitration Reactions of Shell Sproy Base under PUREX Waste Recovery Process Conditions, HW-26517, General Electric Company, Richland, Washington.

Wagner, R. M., 1953, Investigation of Explosive Characteristics of PUREX Solvent Decomposition Products (Red Oil), HW-27492, General Electric Company, Richland, Washington. 


\section{DISTRIBUTION}

\section{Number of Copies}

\section{QFESITE}

4

Los Alamos National Laboratory

Los Alamos. New Mexico
S. F. Agnew
S. Eisenhawer
L. H. Sullivan
J. G. Watkin

3

\section{Savannah River Site}

Aiken, South Carolina

G. Geiger

M. L. Hyder

M. Thompson

2 Idaho National Engineering Laboratory

Idaho Falls. Idaho

\section{R. E. Felt}

W. Lussie

1 Lawrence Livermore National Laboratory

Livermore, California

\section{W. Gray}

2 U.S. Department of Energy

Washington, DC

F. C. Gilbert

F. E. Witmer 


\section{DISTRIBUTION (cont)}

1 Japan Nuclear Fuel Limited

Fukokuseimei Bldg.

2-2.2-Chome, Uchisaiwai-cho

Chivoda-ku,

Tokvo 100. Japan

Dr. Shingo Matsuoka

1 Science and Technology Agency

2-2-1. Kasumigseli. Chiyoda-ku,

Tokyo 100, Japan

Mansanori Shinano

1 Power Reactor and Nuclear Fuel Development Corp.

Tokai-mura, Ibaraki-ken

319-11 Japan

Dr. Yusuke Kuno

1 Japan Atomic Energy Research Institute

Tokai-mura. Naka-gun

Ibaraki-ken

319-11 Japan

Mitsuru Maeda

ONSITE

2 U.S. Department of Energy, Richland Operations Office

W. A. Ruhlman

T5-50

D. W. Templeton

R3-81

4

Pacific Northwest Laboratory

L. L. Burger

P7-25

G. J. Lumetta

P7-25

J. L. Ryan

P7-25

J. L. Swanson

P7-25 


\section{DISTRIBUTION (cont)}

H. Babad

G. S. Barney (10)

D. B. Bechtold

M. L. Bell

D. R. Bratzel

R. J. Cash

S. A. Colby

T. D. Cooper (10)

J. A. Compton

R. G. Cowan

C. H. Delegard

F. D. Fisher

M. W. Gibson

J. C. Hamrick

H. D. Harmon

D. W. Heal

D. L. Herting

B. E. Hey

J. R. Jewett

S. A. Jones

C. M. Kronvall

E. J. Kosiancic

W. S. Lewis

R. M. Marusich

A. L. Ramble

G. W. Reddick

R. C. Roal

L. H. Rodgers

J. J. Roemer

J. E. Shapley

J. P. Sloughter

C. S. Sutter

R. W. Szempruch

R. J. Thompson

R. E. Van der Cook

E. C. Vogt

C. L. Volkman

E. V. Weiss

W. I. Winters

D. D. Wodrich
R2-78

T5-12

T6-09

T6-16

L5-31

R2-78

L4-75

T5-12

T5-12

L5-31

T6-09

T5-12

T5-55

T4-18

R2-52

H4-68

T6-09

T6-09

T6-09

T5-12

T5-53

T6-16

T5-55

H4-60

H4-68

H5- 49

G6-08

T5-54

T5-55

H4-68

T6-07

T5-12

T4-18

S6-17

S6-17

T5-50

T4-19

R3-50

T6-50

R2-85 
WHC-EP-0737

\section{DISTRIBUTION (cont)}

L. F. Wojdac

J. J.-Zimmer Central Files

IRA
T3-01

H4-67

L8-04

H4-17 n 